\title{
1 Free spermidine evokes superoxide radicals that manifest toxicity
}

3 Vineet Kumar ${ }^{1 \ddagger}$, Rajesh Kumar Mishra ${ }^{1+}$, Debarghya Ghose $^{1}$, Arunima Kalita ${ }^{1}$, Anand Prakash ${ }^{1}$,

4 Gopa Mitra ${ }^{2}$, Amit Arora $^{1 s^{*}}$ and Dipak Dutta ${ }^{1 *}$

$5 \quad{ }^{1}$ CSIR Institute of Microbial Technology, Chandigarh India

$6{ }^{2}$ Division of Molecular Medicine, St. John's Research Institute, St. John's Medical college,

7 Bangalore, India

$8 \quad{ }^{\ddagger}$ Present address: Regional Centre for Biotechnology, Faridabad, Haryana, India

$9 \S$ Present address: Department of Medical Microbiology, Post Graduate Institute of Medical

10 Education and Research, Research Block A, Sector-12, Chandigarh- 160012, India.

12 Running Title: Spermidine triggers superoxide radical production

$14{ }^{*}$ Address correspondence to Dipak Dutta, dutta@imtech.res.in

$15+$ Vineet Kumar and Rajesh Kumar Mishra contributed equally to this work

17 Keywords: Escherichia coli, Staphylococcus aureus, SpeG, spermidine toxicity, superoxide 


\section{Abstract}

Spermidine and other polyamines alleviate oxidative stress, yet excess spermidine seems

0 toxic to Escherichia coli unless it is neutralized by SpeG, an enzyme for the spermidine N-acetyl transferase function. Besides, a specific mechanism of SpeG function conferring pathogenic fitness to Staphylococcus aureus USA300 strain is unknown. Here, we provide evidence that although spermidine mitigates oxidative stress by lowering hydroxyl radical and hydrogen peroxide levels, excess of it simultaneously triggers the production of superoxide radicals, thereby causing toxicity in the E. coli $\Delta$ speG strain as well as naturally SpeG-deficient S. aureus RN4220 strain. However, wild-type E. coli and S. aureus USA300 with a horizontally-acquired spe G gene tolerate applied exogenous spermidine stress. Furthermore, we demonstrate that while RNA-bound spermidine inhibits iron oxidation, free spermidine interacts and oxidizes the iron to evoke superoxide radicals directly. Superoxide radicals thus generated, further affects redox balance and iron homeostasis. Since iron acquisition and metabolism in the host tissues is a challenging task for S. aureus, the current findings helped us explain that the evolutionary gain of SpeG function by S. aureus USA300 strain allows it to neutralize exogenous spermidine- and spermine-mediated toxicity towards iron metabolism inside the host tissues. 


\section{Introduction}

Polyamines are ubiquitously present in all life forms. They tweak a diverse array of biological processes, e.g., nucleic acid and protein metabolism, ion channel functions, cell growth and differentiation, mitochondrial function, autophagy and aging, protection from oxidative damage, actin polymerization, and perhaps many more (Casero et al., 2018; Gawlitta et al., 1981; Madeo et al., 2018; Michael, 2018; Miller-Fleming et al., 2015; Oriol-Audit, 1978; Pegg, 2016; Pegg, 2018; Pohjanpelto et al., 1981; Tabor and Tabor, 1984; Wallace et al., 2003). The cationic amine groups of polyamines can avidly bind to the negatively charged molecules, such as RNA, DNA, phospholipids, etc. (Igarashi et al., 2000; Miyamoto et al., 1993; Schuber, 1989; Tabor and Tabor, 1984). Polyamines have been demonstrated to protect DNA from reactive oxygen species (ROS) such as singlet oxygen, hydroxyl radical $(\bullet \mathrm{OH})$, or hydrogen peroxide $\left(\mathrm{H}_{2} \mathrm{O}_{2}\right)$ (Balasundaram et al., 1993; Ha et al., 1998a; Ha et al., 1998b; Jung and Kim, 2003; Khan et al., 1992a; Khan et al., 1992b; LØVaas, 1996; Pegg, 2018; Stewart et al., 2018). Indeed, knocking out polyamine biosynthesis enzymes from $E$. coli and yeast confers toxicity to oxygen, superoxide anion radical $\left(\mathrm{O}_{2}^{-}\right)$, and $\mathrm{H}_{2} \mathrm{O}_{2}$ (Balasundaram et al., 1993; Chattopadhyay et al., 2003; Chattopadhyay et al., 2006; Eisenberg et al., 2009).

Most prokaryotes, including E. coli synthesize cadaverine, putrescine, and spermidine, while higher eukaryotes additionally synthesize spermine. E. coli also acquires spermidine and putrescine from the surrounding medium (Igarashi and Kashiwagi, 2000; Miller-Fleming et al., 2015). However, polyamine in excess is toxic to the organisms unless polyamine homeostasis in the cell is operated at the levels of export, synthesis, inactivation, and degradation (Miller-Fleming et al., 2015). Notably, spermine/spermidine N-acetyl transferase (SSAT or SpeG), which inactivates spermidine and spermine, constitutes the most potent polyamine homeostasis 
71 polyamine nor encodes the SpeG enzyme. Thus, S. aureus strains are inherently hypersensitive to

72 spermidine (Joshi, 2012). However, S. aureus USA-300 lineage, which is evolved through

73 acquiring speG gene nested in the Arginine Catabolic Mobile Element (ACME), is exceptionally

74 pathogenic (Joshi, 2012). The mechanism behind such a phenomenon is entirely unknown.

A tremendous volume of work has been dedicated to unravel the biological importance of spermidine and its homeostasis mechanisms. It has also been known for long that spermidine (or spermine) in excess is toxic to the organisms and viruses (Pegg, 2013). It has been proposed that the excess polyamines may affect protein synthesis by binding to acidic sites in macromolecules, such as nucleic acids, proteins and membrane, and by displacing magnesium from these sites (Pegg, 2013; Limsuwun and Jones, 2000). However, a precise molecular detail of spermidine toxicity is not yet understood. In this study, we decipher a unique molecular mechanism of spermidine toxicity in bacteria. We find the intertwined relationships among spermidine toxicity, iron metabolism, and $\mathrm{O}_{2}^{-}$radical production in bacteria.

\section{Results}

\section{Spermidine stimulates $\mathrm{O}_{2}^{-}$production while inhibits $\bullet \mathrm{OH}$ and $\mathrm{H}_{2} \mathrm{O}_{2}$ production in $E$. coli} (Igarashi and Kashiwagi, 2000; Miyamoto et al., 1993). However, this level is expected to be concentrations of exogenous spermidine that sufficiently inhibits the growth of $\Delta s p e G$, but not WT

91 strain, we added various amounts of spermidine in the growth medium. WT cells showed a modest reduction in growth up to $6.4 \mathrm{mM}$ of spermidine concentration (Figure 1 - figure supplement 1). 
93 On the contrary, $\Delta s p e G$ strain exhibited a striking decrease in growth when supplemental

94 spermidine level was > $3.2 \mathrm{mM}$ (Figure 1 - figure supplement 1 ). Therefore, we chose spermidine

95 concentration $\geq 3.2 \mathrm{mM}$ for our further experiments.

Although spermidine is generally considered an anti-ROS agent (Balasundaram et al.,

97 1993; Chattopadhyay et al., 2003; Chattopadhyay et al., 2006; Ha et al., 1998a; Ha, et al., 1998b;

on the levels of individual ROS species in spermidine-enriched and spermidine-deficient conditions is missing. To address this, we incubated E. coli strains with 2',7'dichlorodihydrofluorescein diacetate (H2DCFDA), and dihydroethidium (DHE) probes, which generate fluorescent compounds reacting with one-electron-oxidizing species such as $\bullet \mathrm{OH}$, and fluorescence intensity (MFI) of H2DCFDA was increased about 1.8-fold in the spermidine synthase-defective $(\Delta s p e E)$ strain, while significantly decreased in $\Delta s p e G$ strain (Figure 1A). Spermidine treatment further decreased the H2DCFDA fluorescence in $\triangle$ speG strain (Figure 1A). Similarly, the relative MFI of DHE probe was increased significantly (1.9-fold) in $\Delta$ speE strain of al., 2018). 
production, are in contrary to the generic idea that suggests spermidine is exclusively an anti-ROS agent (Balasundaram et al., 1993; Chattopadhyay et al., 2003; Chattopadhyay et al., 2006; Ha et al., 1998a; Ha et al., 1998b; Khan et al., 1992a; Khan et al., 1992b; Pegg, 2018; Stewart et al., 2018). In another assay, we determined that $\Delta s p e E$ and the spermidine-fed $\Delta s p e G$ strains release substantially low levels of $\mathrm{H}_{2} \mathrm{O}_{2}$ compared to the untreated counterpart and WT cells (Figure 1C).

Next, we allowed WT and $\Delta s p e G$ strains to grow against the spermidine-diffusing wells on agar plates in aerobic and anaerobic conditions (Figure 1D). A far wider zone of inhibition (ZOI) of growth for $\Delta s p e G$ strain was observed compared to WT under aerobic condition (Figure 1D), while a narrow ZOI was observed under anaerobic conditions for both strains (Figure 1D). This data confirms that $\mathrm{O}_{2}^{-}$production is the major cause of the observed spermidine toxicity.

If spermidine induces $\mathrm{O}_{2}^{-}$production, superoxide dismutase (SOD) genes (e.g., sodA and $s o d B)$ would play vital roles. Therefore, the serial dilutions of $\Delta \operatorname{spe} G \Delta \operatorname{sod} A, \Delta s p e G \Delta \operatorname{sod} B$, and $\Delta \operatorname{spe} G \Delta \operatorname{sod} A \Delta \operatorname{sodB}$ mutants were spotted on LB-agar plates to observe that all the double and triple mutants showed higher growth defects than $\Delta s p e G$ strain under spermidine stress (Figure 1E). However, the cell viability of the double mutants was similar to the $\Delta$ spe $G$ strain, while the triple mutant exhibited an accelerated loss of cell viability, in the presence of spermidine (Figure 1F). When we overexpressed $\operatorname{sod} A$ in the $\Delta \operatorname{spe} G \Delta \operatorname{sod} A$ strain from a plasmid, pBAD-sodA, the growth defect was suppressed (Figure 1E) and the cell viability was remarkably restored under spermidine stress (Figure 1F). Note that, unlike $\Delta$ spe $G$ strain, the single mutants show growth and viability similar to the WT strain in the presence or absence of spermidine (Figure 1E-F - figure supplement 1). This data confirms that the absence of SOD enzymes aggravates $\mathrm{O}_{2}{ }^{-}$toxicity in the spermidine-fed $\Delta$ spe $G$ strain. 


\section{SpeG-negative $S$. aureus also generates $\mathrm{O}_{2}^{-}$under spermidine stress}

As mentioned earlier, $S$. aureus strains do not synthesize polyamines and usually they are speG-negative (Joshi, 2012). One such speG-negative S. aureus, RN4220 strain, encounters hostderived spermidine/spermine while invading host tissues. Unlike the RN4220 strain, the USA300 strain of $S$. aureus is a superior pathogen partly due to horizontal acquisition of speG in evolution (Joshi, 2012). Therefore, spermidine stress would likely evoke $\mathrm{O}_{2}^{-}$radicals in the $S$. aureus RN4220 but not in USA300 strain. Applying $3.2 \mathrm{mM}$ exogenous spermidine, we confirmed that similar to the E. coli $\Delta s p e G$ strain, DHE fluorescence was significantly increased in $S$. aureus RN4220 strain, while spermidine treatment failed to elevate DHE fluorescence in the USA300 strain (Figure 2A). Furthermore, an extremely wide ZOI of growth of RN4220 as compared to the USA300 strain under aerobic condition indicate that spermidine is toxic in the absence of speG due to production of $\mathrm{O}_{2}^{-}$anions (Figure 2B). These results generalize our observation that spermidine-induced $\mathrm{O}_{2}^{-}$production exerts toxicity in bacteria.

Similar to the results for E. coli $\Delta$ speG strain, spermidine also decreases the level of $\bullet \mathrm{OH}$ radicals in RN4220 strain, as indicated by the modest decrease (0.65-fold) in H2DCFDA fluorescence (Figure 2C). However, no significant change in the H2DCFDA fluorescence was observed in USA300 strain (Figure 2C). In contrast to E. coli $\Delta$ speG strain, the S. aureus RN4220 and USA300 strains inherently produces low levels of $\mathrm{H}_{2} \mathrm{O}_{2}$ (Figure 2D; compare it with Figure 1C). Further spermidine treatment had no discernible effect on the $\mathrm{H}_{2} \mathrm{O}_{2}$ levels (Figure 2D).

\section{$\mathrm{O}_{2}^{-}$production under spermidine stress affects cellular redox state}

Antioxidant chemicals, viz. Tiron (Tr), sodium pyruvate (SP), and thiourea (TU) scavenge $\mathrm{O}_{2}{ }^{-}, \mathrm{H}_{2} \mathrm{O}_{2}$, and $\bullet \mathrm{OH}$, respectively (Bleeke et al., 2004; Franco et al., 2007). Whereas, Nacetylcysteine (NAC) and ascorbate counterbalance oxidative stress replenishing glutathione 
161 levels and donating electrons to reducing partners (Nimse and Pal, 2015; Sun, 2010). We show

162 that Tr, NAC, and ascorbate, but not SP and TU, rescued the spermidine-mediated growth

163 inhibition phenotype (Figure 3A). This observation confirms that the $\mathrm{O}_{2}{ }^{-}$stress perturbing redox

164 environment is the route of spermidine toxicity.

The reduced nicotinamide adenine dinucleotide phosphate (NADPH) is a potent reducing

agent. NADPH drives glutathione and thioredoxin cycles, thereby producing reduced forms of

167 glutathione (GST), glutaredoxins, and thioredoxins to cope up with oxidative stress. A large

168 fraction of NADPH in E. coli is provided by a Glucose-6-phosphate 1-dehydrogenase (Zwf)

catalyzed reaction (Olavarría et al., 2012). We show that both the growth and viability of

$\Delta s p e G \Delta z w f$ double mutant were significantly affected compared to the $\Delta s p e G$ strain under

171 spermidine stress (Figure 3B and 3C). Complementing $\Delta s p e G \Delta z w f$ with a plasmid, pBAD-zwf,

172 rescues the growth defect and mortality under spermidine stress (Figure 3B and 3C). We estimated

173 the total NADP $\left(\mathrm{NADP}_{\mathrm{t}}\right)$, total glutathione $\left(\mathrm{GS}_{\mathrm{t}}\right)$, and their oxidized (NADP+ and GSSG) and

174 reduced (NADPH and GSH) species in the WT and $\Delta$ spe $G$ strains grown in the absence and

175 presence of spermidine. The relative levels of total and reduced species of NADP and GST were

176 decreased significantly in the spermidine-fed $\Delta$ spe $G$ strain (Figure 3D and 3E). NAD serves as the

177 precursor for NADP production. However, the levels of total (NADt), oxidized (NAD+), and

178 reduced $(\mathrm{NADH})$ did not alter significantly (Figure 3F). Nevertheless, the NAD+ to NADH ratio

179 was significantly increased in the $\Delta s p e G$ strain compared to WT cells (Figure $3 F$ ). No significant

180 increase of the ratios was observed by adding spermidine in the growth medium of WT and $\Delta$ spe $G$

181 strain (Figure 3F). In consistence with the increased ratio of NAD+ to NADH, the level of ATP

182 was declined in $\Delta s p e G$ strain compared to the unfed WT (Figure 3G). ATP level was further 


\section{Spermidine affects iron-sulfur cluster biogenesis and blocks the induction of SoxR regulon}

To understand the global impact of spermidine toxicity, we performed a microarray experiment on the $\Delta$ spe $G$ strain in the presence and absence of spermidine. The genes that were >2-fold downregulated are involved in flagellar biogenesis, acid resistance, hydrogenase function, nitrogen metabolism, electron transport, aromatic and basic amino acid metabolism, etc. (Figure shock, and other stress factors (groL, groS, dnaK, hdeAB, ibpAB, uspAB, etc.) were also highly upregulated category, the genes that encode for the ribosome, RNA polymerase, transcription factors, DNA polymerase, and enzymes for the fatty acid biosynthesis and iron-sulfur cluster (isc) biogenesis were prominent (Supplementary file 1 and Figure 4A). Many genes regulated by Fis and IHF were activated or repressed in our microarray indicating that spermidine could activate Fis and IHF regulon (Supplementary file 2). However, $\Delta s p e G \Delta f i s$, but not $\Delta$ speG $\Delta$ ihfA strain, generated small colonies upon overnight incubation (Figure 4 - figure supplement 1), suggesting that the role of Fis regulator is critical under spermidine stress. RTqPCR experiment was performed to validate the microarray data partially (Figure 4 - figure 201 supplement 2).

Iron-sulfur center of SoxR senses the levels of cellular $\mathrm{O}_{2}{ }^{-}$or NO (Fujikawa et al., 2017; 

reporter plasmid expressing gfpmut2 from the soxS promoter $\left(\mathrm{P}_{\text {soxs }}\right.$ gfpmut2), and RKM1 strain containing a chromosomally fused lacZ reporter under sodA promoter $\left(\mathrm{P}_{\text {sodA-lacZ }}\right)$ (Table 1$)$, we did not find any transcriptional activation of $\operatorname{sox} S$ and $\operatorname{sodA}$ promoters (Figure 4 - figure supplement 2). Therefore, we suspected whether spermidine in excess blocks the $\mathrm{O}_{2}^{-}$-mediated activation of SoxR, thereby aggravating $\mathrm{O}_{2}^{-}$toxicity. To probe this possibility, we induced $\mathrm{O}_{2}{ }^{-}$ production by menadione to observe $\mathrm{P}_{\text {soxs }}$ gfpmut2 reporter induction and chased it by spermidine in the $\Delta$ speG strain. Spermidine suppressed the menadione-induced GFP reporter fluorescence, suggesting that spermidine indeed blocks SoxR-mediated activation of soxS in E. coli (Figure 4B). A possible mechanism of spermidine-mediated SoxR inactivation is discussed. Among other ROSresponsive genes, the catalase coding genes ( $k a t E$ and $k a t G)$ were downregulated, (Figure 4A) while no change was observed in the expression of $a h p C F$ genes under spermidine stress (GEO accession \#154618). Using pUA66_ahpC and pUA66_katG reporter plasmids ( $\mathrm{P}_{a h p C-g f p m u t 2}$ and $\mathrm{P}_{k a t G^{-}}$gfpmut2, respectively), we validated these microarray observations (Figure 4 - figure supplement 2). unchanged expression of SodA and a decreased expression of KatG in the spermidine-treated $\Delta s p e G$ strain compared to untreated counterparts (Figure 4C and 4D). However, SodA level was modestly elevated in the $\Delta s p e G$ strain, and the spermidine-treated WT strain, in contrast to the untreated WT strain (Figure 4C). Contrary to the microarray data, a profound increase in AhpC

227 level was observed while growing WT or $\Delta s p e G$ cells in the presence of spermidine, indicating a 228 translational elevation of AhpC level under spermidine stress (Figure 4E). Increased AhpC level 229 indicating the activation of alkyl hydroperoxidase (AhpCF) enzyme, could be responsible for the 
230

231

232

233

234

235

236

237

238

239

240

241

242

243

244

245

246

247

248

249

250

251

252

decline in cellular $\mathrm{H}_{2} \mathrm{O}_{2}$ level (Figure 1C). Thus, declined $\mathrm{H}_{2} \mathrm{O}_{2}$ concentration could be the limiting factor for the cellular $\bullet \mathrm{OH}$ radical production under spermidine stress (Figure 1A).

$\mathrm{O}_{2}^{-}$has the potential to oxidize the solvent-exposed iron-sulfur clusters of E. coli dehydratases, aconitase, and fumarase enzymes to liberate free $\mathrm{Fe}^{2+}$ (Benov, 2001; Fridovich, 1986; Imlay, 2008). Therefore, supplementation of $\mathrm{Fe}^{2+}$ ions helps to repair the damaged clusters (Gardner and Fridovich, 1992; Imlay, 2008). Consistently, we observed that the declined aconitase activity in the spermidine-stressed $\Delta$ spe $G$ strain was rescued by supplemental $\mathrm{Fe}^{2+}$ ion (Figure $4 \mathrm{~F}$ ). Besides, we show that the intracellular level of iron in the $\Delta s p e G$ strain was decreased more than three-fold in the presence of spermidine (Figure 4G). Interestingly, the iron content in the S. aureus strains was found to be substantially lower than the E. coli WT cells (Figure 4G). Furthermore, while the iron content of USA300 strain remained indifferent, the iron content of RN4220 strain was significantly declined under spermidine stress (Figure 4G). The iron scarcity was also reflected in the gene expression pattern of IscR regulon. IscR forms a functional holoenzyme with the iron-sulfur cluster. The de-repression of iron-sulfur cluster biogenesis operon (iscRSUA$h s c B A-f d x-i s c X$ ) in the microarray (Figure 4A) signifies the presence of non-functional apo-IscR under the scarcity of cellular $\mathrm{Fe}^{2+}$ ion (Schwartz et al., 2001). Supplementation of $\mathrm{Fe}^{2+}$ salt in the LB-agar plate to rescue the growth of spermidine-fed $\Delta$ spe $G$ strain supports this claim (Figure 4H). Spermidine also activated $r s x A$ and $r s x B$ (Figure 4A), which encode the critical components of the iron-sulfur cluster reducing system of SoxR (Koo et al., 2003). The level of manganese, an antioxidant metal that determines sodA activity, is usually increased under iron scarcity (Kaur et al., 2014; Kaur et al., 2017; Martin et al., 2015; Waters et al., 2011). However, a modest decrease in the level of cellular manganese under spermidine stress was observed (Figure 4G). The low level of manganese could slow down the rate of dismutation of $\mathrm{O}_{2}{ }^{-}$anion compromising SodA 
253 function, thereby elevating the $\mathrm{O}_{2}{ }^{-}$anion levels in the spermidine-treated cells. Finally, we spotted

254 the cultures of serially diluted $E$. coli strains to show that the deletion of two individual genes (isc $U$

255 and $y g f Z$ ), which are involved in the iron-sulfur cluster biogenesis (Waller et al., 2010), affects the

256 growth of the spermidine-treated $\Delta$ speG strain (Figure 4I). Interestingly, the $\Delta$ speG $\Delta$ soxS strain

257 was more sensitive to spermidine than the $\Delta s p e G$ strain (Figure 4I), indicating that the basal level

258 of soxS expression has some potential to ameliorate $\mathrm{O}_{2}^{-}$under spermidine stress. Although marA

259 and $\operatorname{mar} B$ genes were expressed at the highest level in the spermidine-stressed $\Delta$ spe $G$ strain

260 (Figure 4A), $\Delta s p e G \Delta$ marA and $\Delta s p e G \Delta \operatorname{mar} B$ strains did not show any difference in growth

261 compared to $\Delta s p e G$ strain under spermidine stress (Figure 4I). Note that, unlike $\Delta s p e G$ strain, the

262 single mutants grow similarly to the WT strain in the presence or absence of spermidine (Figure

2634 I and Figure 1- figure supplement 1).

264 Free spermidine interacts and oxidizes $\mathrm{Fe}^{2+}$ ion to generate superoxide radicals in vitro

To probe whether spermidine directly interacts with iron, we performed isothermal titration

267 of spermidine with $\mathrm{Fe}^{3+}$ generated exothermic peaks indicating a standard binding reaction with a

268 stoichiometry $(\mathrm{N})$ of 0.711 (Figure 5A). On the other hand, titration of spermidine with $\mathrm{Fe}^{2+}$ in

269 two different isothermal conditions produced consistent and complex patterns (Figure 5B and 5C).

270 To explain it, we divided the pattern into two halves. In the first half, $\mathrm{Fe}^{2+}$ injections to spermidine

271 generated alternate exothermic and endothermic peaks till the ratio of spermidine to $\mathrm{Fe}^{2+}$ reaches

272 about 1:1.3 (Figure 5B and 5C). In the second half of the profile, after the ratio of spermidine to

$273 \mathrm{Fe}^{2+}$ crosses 1:1.3, no endothermic peaks were observed, and a gradual shortening of exothermic

274 peaks was generated, leading to saturation (Figure 5B and 5C). From the first half of pattern, we 
275 suspected $\mathrm{Fe}^{2+}$ interaction with spermidine also involves some other reactions, such as oxidation

276 of the $\mathrm{Fe}^{2+}$ to generate $\mathrm{Fe}^{3+}$ and $\mathrm{O}_{2}^{-}, \mathrm{Fe}^{3+}$ release, and subsequent $\mathrm{Fe}^{3+}$ binding to spermidine.

278 spermidine by increasing amounts of $\mathrm{Fe}^{2+}$ iron followed by assessing the level of $\mathrm{Fe}^{2+}$ by using

279 bipyridyl chelator. Chelation of $\mathrm{Fe}^{2+}$ ions by bipyridyl generates pink color indicating $\mathrm{Fe}^{2+}$ levels.

280 No color formation was observed till the ratio of spermidine to $\mathrm{Fe}^{2+}$ reaches 1:1.3 (Figure 5D), a

281 number that exactly matches with the ratio of spermidine to $\mathrm{Fe}^{2+}$ in the first half of ITC experiments

282 (Figure 5B and 5C). The color formation starts appearing when the ratio crosses 1:1.3 (Figure 5D),

283 suggesting that 1 molecule of spermidine (or 10 molecules) exactly oxidizes 1.3 molecules (or 13

284 molecules) of $\mathrm{Fe}^{2+}$. The colorimetric values overlap with the standard curve when reactions were

285 under anoxic condition, indicating $\mathrm{Fe}^{2+}$ was not oxidized (Figure 5D). We used nitro blue

286 tetrazolium (NBT) dye to check whether the loss of one electron from $\mathrm{Fe}^{2+}$ generates $\mathrm{O}_{2}^{-}$anion

287 under spermidine stress. An increased NBT absorption at $575 \mathrm{~nm}$ till the ratio of spermidine to $\mathrm{Fe}^{2+}$

288 reaches 1:1.3 confirms that 1 molecule (or 10 molecule) of spermidine interacts with 1.3 molecules

289 (or 13 molecules) of $\mathrm{Fe}^{2+}$ generating 1.3 molecules (or 13 molecules) $\mathrm{O}_{2}^{-}$anion radical (Figure

290 5E). From the stoichiometry of 0.711 (which is close to 0.5) (Figure 5A), we postulate that two

291 spermidine and one $\mathrm{Fe}^{3+}$ together could form a hexadentate co-ordination complex with an

292 octahedral geometry (Figure 5F). It appears that when spermidine molecules engaged to form a

293 hexadentate co-ordination complex with $\mathrm{Fe}^{2+}$, the former helps oxidizing latter to form $\mathrm{Fe}^{3+}$ in

294 sufficient concentrations. $\mathrm{Fe}^{3+}$ finally forms coordination complex with spermidine (Figure 5F). It

295 may be noted that the binding of spermidine and $\mathrm{Fe}^{3+}$ is entirely enthalpy driven, as indicated by

296 a large negative $\Delta \mathrm{H}$. The negative entropy $(\Delta \mathrm{S})$ value presumably results from the ordering of 
spermidine from an extended conformation to a compact and rigid one after metal chelation (Figure $5 \mathrm{~A})$.

The cellular spermidine barely exists as a "free" species; rather, majority of them remain "bound” with RNA, DNA, nucleotides, and phospholipids (Igarashi and Kashiwagi, 2000; phosphate-containing biomolecules have the inherent property to inhibit iron oxidation blocking enhances the inhibitory effects of these biomolecules towards iron oxidation. Consistent with the report (Tadolini, 1988b), we noticed that $1 \mu \mathrm{g}$ of RNA inhibited the oxidation of $200 \mu \mathrm{M} \mathrm{Fe}{ }^{2+}$.

306 The presence of $10 \mu \mathrm{M}$ spermidine further decreased iron oxidation (Figure 5G). However, increasing the concentrations of spermidine $(50,100$, and $200 \mu \mathrm{M})$, accelerated iron oxidation gradually (Figure 5G). This data clearly indicates that cell maintains a level of cellular spermidine that may remain optimally bound with the biomolecules inhibiting $\mathrm{O}_{2}^{-}$generation. However, when homeostasis fails due to spe $G$ deletion, excess spermidine accumulates that can remain in a "free"form inducing $\mathrm{O}_{2}^{-}$radical toxicity.

\section{Discussion}

Our study presented in this paper answers why spermidine homeostasis is intriguingly finetuned in bacteria. We provide clear-cut evidence that excess spermidine, which remains as a free species (Figure 5G), stimulates the production of toxic levels of $\mathrm{O}_{2}{ }^{-}$radicals in E. coli and $S$. aureus, unless spermidine is inactivated by the SpeG-mediated acetylation (Figure 1 and Figure

317 2). $\mathrm{O}_{2}^{-}$anion thus generated affects cellular redox balance (Figure 3) and damages iron-sulfur 318 clusters of the proteins (Figure 4). Since spermidine directly interacts with $\mathrm{Fe}^{2+}$ (Figure 5), it may 319 abstract iron from some of the iron-sulfur clusters, thereby inactivating some of the proteins. On 
the other hand, when spermidine level is at optimum, most of it remain as bound form with the biomolecules, thereby slows down iron oxidation and subsequent $\mathrm{O}_{2}^{-}$production (LØVaas, 1996; Tadolini, 1988a; Tadolini, 1988b) (Figure 5G). Thus, spermidine-deficiency would enhance the rate of iron oxidation (Figure $5 \mathrm{G}$ ), leading to the production of $\mathrm{O}_{2}{ }^{-}$and $\bullet \mathrm{OH}$ radicals (Figure $1 \mathrm{~A}$ and 1B). This is why spermidine is a double-edged sword where in excess, it provokes $\mathrm{O}_{2}{ }^{-}$anion production, and in scarcity, it leads to increased $\mathrm{O}_{2}{ }^{-}$anion and $\bullet \mathrm{OH}$ radical production.

Polyamines remain protonated at physiological $\mathrm{pH}$, yet they are able to coordinate several positively charged metal ions, such as $\mathrm{Ni}^{2+}, \mathrm{Co}^{2+}, \mathrm{Cu}^{2+}$, and $\mathrm{Zn}^{2+}$, possibly via charge neutralization by counterions that reduces the Coulombic repulsion between spermidine and the metals (LØVaas, 1996). Similar charge neutralization of the nitrogen atoms of spermidine likely allows coordinate covalent bonds with $\mathrm{Fe}^{3+}$ (Figure 5F). About 10 spermidine molecules oxidize $\mathrm{Fe}^{2+}$ to generate $13 \mathrm{Fe}^{3+}$ cations and equivalent numbers of $\mathrm{O}_{2}^{-}$radicals (Figure 5B and 5C). When sufficient concentration of $\mathrm{Fe}^{3+}$ is generated, two spermidine molecules coordinate one $\mathrm{Fe}^{3+}$ to form a hexadentate complex with an octahedral geometry (Figure 5F). We substantiated this in vitro spermidine-mediated iron oxidation and subsequent $\mathrm{O}_{2}^{-}$radical production phenomena (Figure 5), showing that cells are highly toxic to the spermidine under aerobic condition but not under anaerobic condition (Figure $1 \mathrm{~J}$ and $2 \mathrm{~B}$ ).

Usually, abundant $\mathrm{O}_{2}^{-}$level leads to $\mathrm{H}_{2} \mathrm{O}_{2}$ and $\bullet \mathrm{OH}$ production. However, despite elevated $\mathrm{O}_{2}{ }^{-}$production, spermidine lowers $\mathrm{H}_{2} \mathrm{O}_{2}$ and $\bullet \mathrm{OH}$ levels in $\Delta s p e G$ strain. (Figure $1 \mathrm{C}$ and $1 \mathrm{~A}$ ). The declined $\mathrm{H}_{2} \mathrm{O}_{2}$ level could be attributed to the slower rate of $\mathrm{O}_{2}{ }^{-}$anion dismutation due to the failure of $\operatorname{sodA}$ activation (Figure 4C - figure supplement 2) and the activation of alkyl hydroperoxidase (AhpCF) that neutralizes $\mathrm{H}_{2} \mathrm{O}_{2}$, represented by $\mathrm{AhpC}$ overexpression (Figure 4D). A low level of cellular manganese (Figure 4G) could also limit SodA activity. Besides, the activation of IscR 
regulon (Figure 4A), the low cellular iron content (Figure 4G), and the rejuvenation of cell growth by $\mathrm{Fe}^{2+}$ supplementation (Figure $4 \mathrm{H}$ ) indicate that the spermidine presumably lowers the $\mathrm{Fe}^{2+} / \mathrm{Fe}^{3+}$ ratio in $\Delta$ spe $G$ strain. Thus, the decreased level of $\mathrm{Fe}^{2+}$ and $\mathrm{H}_{2} \mathrm{O}_{2}$ (Figure $4 \mathrm{G}$ and 1C) could potentially diminish cellular $\bullet \mathrm{OH}$ radical production in the spermidine-fed cells (Figure $1 \mathrm{~A}$ ). We have summarized all these observations and hypotheses in the schematic Figure 6.

Interestingly, spermidine stimulates $\mathrm{O}_{2}^{-}$production and blocks $\mathrm{O}_{2}^{-}$-mediated SoxR activation in the $\Delta$ spe $G$ cells (Figure 4B). Since spermidine ubiquitously interacts with DNA and modulates gene expression in many ways (Igarashi and Kashiwagi, 2000; Jung and Kim, 2003; Miyamoto et al., 1993), one possibility could be that excess of it might occlude SoxR-binding to the soxS and sodA promoter regions to activate them. Alternatively, blockage of SoxR activation could result from spermidine-mediated activation of $r s x A$ and $r s x B$ (Figure 4A), which encode the critical components of the iron-sulfur cluster reducing system of SoxR (Koo et al., 2003), to keep SoxR inactive. The third possibility could be that the iron-binding property of spermidine (Figure 5A, 5B, 5C) may allow it to directly abstract iron from the iron-sulfur cluster to inactivate SoxR. Nevertheless, a detailed biochemical study on this aspect is needed to understand the mechanism. Our study clarifies how the horizontal acquisition of $s p e G$ gene could confer a pathogenic advantage to the $S$. aureus USA 300 strain (Eisenberg et al., 2009). S. aureus, a Gram-positive commensal living on human skin, often causes severe disease upon access to deeper tissues. Since most of the iron in mammals exists intracellularly, the extracellular pathogen, $S$. aureus faces hardship and competes with the host for the available iron (Hammer and Skaar, 2011). As spermidine declines cellular iron content and interferes with iron metabolism (Figure 4), it is thus possible that $S$. aureus does not synthesize spermidine. Furthermore, the acquisition of spe $G$ gene could allow S. aureus USA300 to inactivate host-originated spermidine/spermine, thereby to 
maintain cellular iron content (Figure 4G). Corroborating to our findings, a recent observation has

pointed out that spermine stress upregulates iron homeostasis genes, indicating that spermine

(MRSA) (Yao and Lu, 2014). Besides, spermine-mediated iron depletion may be responsible for

Nevertheless, a thorough in vivo host-pathogen interaction study will unravel a specific link between spermine/spermidine and iron depletion in S. aureus.

\section{Methods}

\section{Bacterial strains, plasmids, proteins, and chemicals} triple knockout mutants were generated following the standard procedure described by Datsenko and Wanner (Datsenko and Wanner, 2000). E. coli strain JRG3533 was a generous gift from Dr. 
DG9-DG10, and RK3-RK4 primer pairs (Supplementary file 3), respectively. The PCR products were double-digested at the primer-specific unique restriction sites and inserted into identically digested pET28a (+) plasmid vector so that the 6X his-tagged SodA, KatG, and AhpC proteins are

392 being produced. The protein expression vectors, pET-sodA, pET-ahpC, pET-katG were transformed to BL21 (DE3) cells, and expressions were induced by $0.4 \mathrm{mM}$ IPTG. The overexpressed proteins were purified using Ni-NTA beads. The purified proteins were used to additionally subcloned in $\mathrm{pBAD} / \mathrm{Myc}-\mathrm{His} \mathrm{A}$ vector to get $\operatorname{sodA}$ and $\operatorname{spe} G$ multicopy expressions for complementation assays.

\section{Growth, viability, spermidine sensitivity, and complementation assays}

An automated BioscreenC growth analyzer (Oy growth curves Ab Ltd.) was used to

generate growth curves mentioned in the results. For this purpose, overnight cultures of different strains were diluted in fresh LB medium and grown in the presence and absence of $3.2 \mathrm{mM}$ to 6.4 $\mathrm{mM}$ of spermidine. $10 \mathrm{mM}$ of each of the ROS quenchers (thiourea, Tiron, sodium pyruvate, ascorbate, and NAC) were used wherever mentioned. For viability assays, serially diluted E. coli strains were spread on LB-Agar surface supplemented with $6.4 \mathrm{mM}$ spermidine. We determined

406 the viability under spermidine stress from the number of colonies grown. Zone of inhibitions

407 (ZOI), which appeared following overnight growth of the strains in the presence of $6.4 \mathrm{mM}$ 408 spermidine in the wells on agar plates, were determined both in aerobic and anaerobic conditions. 409 The anaerobic condition was created in an anaerobic petri dish jar using AnaeroGas Pack 3.5L 410 pouches. For complementation experiments, the pBAD-zwf and pBAD-sodA plasmids were 411 transformed into $\Delta s p e G \Delta z w f$, and $\Delta s p e G \Delta s o d A$ strains, respectively, and growth assays were 
412 performed in the presence of spermidine. Since the leaky expressions of $z w f$ and sodA were

413 sufficient to rescue growth defects, induction with arabinose was avoided for this purpose.

The reporter plasmids, pUA66_soxS, pUA66_ahpC,pUA66_katG, were transformed in

$\Delta s p e G$ strain. The transformed cells were grown in the presence or absence of $3.2 \mathrm{mM}$ spermidine.

Wherever mentioned, $25 \mu \mathrm{M}$ menadione was used as a positive control for $\mathrm{O}_{2}{ }^{-}$generation. The

417 cell pellets were washed twice with PBS and dissolved in $500 \mu$ l phosphate buffer saline (PBS).

418 Flow cytometry was done using the Fl1 laser for 0.05 million cells using FACSVerse (BD

419 Biosciences). The mean fluorescence intensity (MFI) values from three biological replicates have

420 been calculated.

\section{Determining relative ROS levels in the cells}

H2DCFDA $(10 \mu \mathrm{M})$ and DHE $(2.5 \mu \mathrm{M})$, were used to measure cellular $\bullet \mathrm{OH}$ and $\mathrm{O}_{2}{ }^{-}$anion,

423 respectively. The cells were grown in the presence or absence of $3.2 \mathrm{mM}$ spermidine. Cells were

424 harvested, washed with PBS, and an equal mass of cell pellets was incubated with DHE or

425 H2DCFDA probes for an hour. The data were acquired using BD accuri F13 laser (for DHE) and

426 Fl1 laser (for H2DCFDA) for 0.05 million cells. The mean fluorescence intensities (MFI) values

427 of triplicate experiments were calculated. For $\mathrm{H}_{2} \mathrm{O}_{2}$ detection, the E. coli cells were grown in the

428 presence or absence of $3.2 \mathrm{mM}$ of spermidine for 4 hours. Cells were harvested and washed with

429 1X M9 minimal media. The equal mass of cells (2.5 mg each) suspended in $6 \mathrm{ml}$ M9 minimal

430 media were incubated for different time points to allow $\mathrm{H}_{2} \mathrm{O}_{2}$ liberation. The relative $\mathrm{H}_{2} \mathrm{O}_{2}$

431 liberation was measured by a Fluorimetric Hydrogen Peroxide Assay kit (Sigma Aldrich).

\section{$432 \quad \beta$-galactosidase and GFP reporter assays}

For the $\beta$-galactosidase assay, the RKM1 strain was grown in the presence or absence of 
$\mathrm{mM} \mathrm{NaH}_{2} \mathrm{PO}_{4}, 10 \mathrm{mM} \mathrm{KCl}$, and $1 \mathrm{mM} \mathrm{MgSO}_{4}$ ) and diluted to $\mathrm{OD}_{600} \sim 0.5$. Promoter activity was measured by monitoring $\beta$-gal expression from single-copy sodA-lac $Z$ transcriptional fusion. 100 $\mu 1$ of $4 \mathrm{mg} / \mathrm{ml} \mathrm{ONPG}$ was used as a substrate, which was cleaved by $\beta$ - galactosidase to produce yellow-colored O-nitrophenol. Colorimetric detection of this compound was done at 420nm. The reporter plasmids, pUA66_soxS, pUA66_ahpC,pUA66_katG, containing GFP-mut2 reporters, were used to determine the promoter activities of $\operatorname{soxS}, \operatorname{ahpC}$, and $k a t G$ genes in the presence or absence of $3.2 \mathrm{mM}$ spermidine. Flow cytometry was done using the FL1 laser for 0.05 million cells using FACSVerse (BD Biosciences) or BD Accuri ${ }^{\mathrm{TM}}$ C6 Plus Flow Cytometer (BD Biosciences) machine.

\section{Western blotting experiments}

Overnight culture of E. coli strains was inoculated in fresh LB medium in 1:100 dilution and grown for 1.5 hours at $37^{\circ} \mathrm{C}$. Next, $3.2 \mathrm{mM}$ of spermidine were added, wherever required and allowed to grow again at $37^{\circ} \mathrm{C}$ for 2.5 hours. Cells were harvested and lysed with B-PER ${ }^{\circledR}$ bacterial protein extraction reagent (Thermo Scientific). The total protein level was checked by the Bradford assay kit (Bio-Rad). $40 \mu \mathrm{g}$ of total cellular proteins from the individual samples were subjected to SDS-PAGE. The proteins were transferred to a nitrocellulose membrane and stained with Ponceau $\mathrm{S}$ to visualize protein resolution and equal loading in the PAGE. Western blotting was performed using polyclonal rabbit primary antibodies and HRP conjugated secondary antibodies. The blots were developed by Immobilon ${ }^{\circledR}$ Forte Western HRP substrate (Millipore).

\section{Isothermal titration calorimetry}

A MicroCal VP-ITC calorimeter, MicroCal Inc., was used for calorimetric measurements to probe the interaction of spermidine with $\mathrm{Fe}^{2+}$ and $\mathrm{Fe}^{3+}$ species. In order to achieve this, $100 \mu \mathrm{M}$ 
of spermidine solution was prepared in $20 \mathrm{mM}$ sodium acetate buffer $(\mathrm{pH} \mathrm{5.5)}$ ) and put into the sample cell. The ligands, $2.1 \mathrm{mM}$ of $\mathrm{FeCl}_{3}$ or ferrous ammonium sulphate, were also dissolved in $\mu 1$ per shot) at 300 seconds intervals into the sample cell containing $1.8 \mathrm{ml}$ of $100 \mu \mathrm{M}$ spermidine.

462 The titration cell was kept at some specific temperature and stirred continuously at $286 \mathrm{rpm}$. The 463 heat of dilution of ligand in the buffer alone was subtracted from the titration data. The data were analyzed using Origin 5.0 software.

\section{2,2'-Bipyridyl and NBT assays}

467 curve for $0 \mu \mathrm{M}$ to $350 \mu \mathrm{M}$ of $\mathrm{Fe}^{2+}$ ion was generated simply by recording $\mathrm{A}_{522}$ in the presence of 2,2'-Bipyridyl. Dissolved oxygen of medium and headspace oxygen was replaced by flushing $\mathrm{N}_{2}$ gas in the medium for 5 minutes to create an anoxic condition as described (Stieglmeier et al.,

470 2009). To check whether spermidine acts as a catalyst for $\mathrm{Fe}^{2+}$ to $\mathrm{Fe}^{3+}$ oxidation, we performed 2 ,

4712 -bipyridyl assay probing leftover $\mathrm{Fe}^{2+}$ after the reaction. For this assay, $100 \mu \mathrm{M}$ of spermidine

472 was incubated with increasing concentrations $(25 \mu \mathrm{M}$ to $350 \mu \mathrm{M})$ of ferrous ammonium sulphate

473 for 10 minutes at room temperature. $900 \mu \mathrm{l}$ of the reaction products were mixed with $90 \mu \mathrm{l} 4 \mathrm{M}$

474 sodium acetate buffer $(\mathrm{pH} 4.75)$ and $90 \mu l$ bipyridyl $(0.5 \%$ in $0.1 \mathrm{~N} \mathrm{HCl})$. The color formation was 475 recorded at $522 \mathrm{~nm}$ (A522) using UV-1800 Shimandzu UV-spectrophotometer. In another 476 experiment, the assay was performed in anoxic condition using rubber capped sealed glass vials

477 containing anoxic reactants and needle-syringe-mediated mixing of the reagents. Here, three 478 different concentrations $(100 \mu \mathrm{M}, 200 \mu \mathrm{M}$, and $300 \mu \mathrm{M})$ of ferrous ammonium sulphate were 479 reacted with $100 \mu \mathrm{M}$ of spermidine for 10 minutes followed by spectrophotometry at $\mathrm{A}_{522}$. The 
481 mixture of $900 \mu \mathrm{l}$ ferrous ammonium sulphate, $90 \mu 1$ sodium acetate buffer, and $90 \mu 1$ bipyridyl

482 solutions.

Iron oxidation in the presence of RNA and spermidine was performed as described

484 (Tadolini, 1988b). $1 \mu \mathrm{g}$ RNA and increasing concentrations of spermidine $(10 \mu \mathrm{M}-200 \mu \mathrm{M})$ were

485

used in $5 \mathrm{mM}$ MOPS buffer, $\mathrm{pH}$ 7.4. The oxidation was started adding $200 \mu \mathrm{M} \mathrm{FeCl}$. The

486 reactions were stopped at desired time point by adding a stop solution (1:1 4M sodium acetate:4M

487 glacial acetic acid) followed by 2,2'-Bipyridyl to detect $\mathrm{Fe}^{2+}$ levels.

We used Nitro blue tetrazolium (NBT) dye to probe whether spermidine-stimulated $\mathrm{Fe}^{2+}$

to $\mathrm{Fe}^{3+}$ oxidation liberates $\mathrm{O}_{2}{ }^{-}$anion in vitro. For this assay, different concentrations of $\mathrm{Fe}^{2+}$ were

incubated with $100 \mu \mathrm{M}$ of spermidine for 2 minutes. $100 \mu \mathrm{l}$ of NBT $(5 \mathrm{mg} / \mathrm{ml})$ was added to the

mixture and incubated at RT for another 5 minutes. The absorbance was recorded at $575 \mathrm{~nm}$ using

492

UV-1800 Shimandzu UV-spectrophotometer.

493 Quantitative real-time PCR (RT-qPCR)

Bacterial mRNAs were isolated by TRIzol $^{\circledR}$ reagent and the Qiagen bacterial RNA

495 isolation Kit. DNase I treatment was done to remove residual DNA contaminant, and the integrity

496 of the mRNA was checked on a $1 \%$ agarose gel. The RNA concentration was determined by a

497 Nano-drop spectrophotometer (Thermo Scientific) and by a UV-1800 Shimandzu UV-

498 spectrophotometer. 200ng of RNA samples, primer pairs (Table 2), and GoTaq ${ }^{\circledR}$ 1-Step RT-qPCR

499 System (Promega) were used for RT-qPCR. Reaction mixture without template were included as

500 negative controls. At least three independent experiments were conducted for the determination of

501 cycle threshold $\left(\mathrm{C}_{\mathrm{T}}\right)$ values. Fold expression change between spermidine-fed and unfed samples

502 was calculated by the $\Delta \Delta \mathrm{C}_{\mathrm{T}}$ method. The values were normalized to the level of bet $B \mathrm{mRNA}$ that 


\section{Other Biochemical assays}

Different colorimetric assay kits (Sigma Aldrich) and ATP Bioluminescence assay Kit CLS II (Roche) were used to detect relative levels of NAD, NADH, GSH, and ATP. Aconitase assay was performed as per the protocol described (Gardner \& Fridovich, 1992). Metal contents were determined by ICP-MS analyses at Punjab Biotechnology Incubator, Mohali, India. The metal concentration in the cell was determined as parts per billion $(\mathrm{mg} / \mathrm{kg})$ of $E$. coli cell pellets.

\section{Microarray experiments and interpretation}

The saturated overnight culture of $\Delta s p e G$ strain was inoculated in the fresh LB medium and grown for 1.5 hours. After that $3.8 \mathrm{mM}$ spermidine was added to one of the flasks, and the cultures were grown further for 2.5 hours. The cell pellets were harvested and washed with PBS, and dissolved in RLT buffer. The microarray was done from Genotypic Technology, Bangalore. The microarray had three probes for each gene on average.

\section{RNA Extraction and RNA Quality Control for Microarray}

E. coli cell pellet was re-suspended in $300 \mu \mathrm{l}$ of $5 \mathrm{mg} / \mathrm{ml}$ lysozyme and incubated at room temperature (RT) for 30 min. Isolation of RNA from E. coli was carried out using Qiagen RNeasy mini kit (Cat \# 74106) as per manufacturer's guidelines. A separate DNase treatment of the isolated total RNA was performed. The purity of the RNA was assessed using the Nanodrop Spectrophotometer (Thermo Scientific; ND-1000), and the integrity of the RNA was analyzed on the Bioanalyzer (Agilent 2100). We considered RNA to be of good quality based on the 260/280 values (Nanodrop), rRNA 28S/18S ratios, and RNA integrity number (RIN) (Bioanalyzer).

\section{Microarray Labeling}

The sample labeling was performed using Quick-Amp Labeling Kit, One Color (Agilent Technologies, Part Number: 5190-0442). 500ng of each sample were denatured along with WT 
527 primer with a T7 polymerase promoter. The cDNA master mix was added to the denatured RNA

528 sample and incubated at $40^{\circ} \mathrm{C}$ for 2 hours for double-stranded cDNA synthesis. Synthesized

529 double-stranded cDNA was used as a template for cRNA generation. cRNA was generated by in

530 vitro transcription, and the Cyanine-3-CTP (Сy3-СТP) dye incorporated during this step and

531 incubated at $40^{\circ} \mathrm{C}$ for $2: 30$ hours. The Cy3-CTP labeled cRNA sample was purified using the

532 Qiagen RNeasy column (Qiagen, Cat \# 74106). The concentration of cRNA and dye incorporation

533 was determined using Nanodrop-1000.

534 Microarray hybridization and scanning

About 4 micrograms of labelled Cy-3-CTP cRNA was fragmented at $60^{\circ} \mathrm{C}$ for 30 minutes, and the reaction was stopped by adding 2X GE HI-RPM hybridization buffer (Agilent

537 Technologies, In situ Hybridization kit, Part Number: 5190-0404). The hybridization was carried 538 out in Agilent's Surehyb Chambers at $65^{\circ} \mathrm{C}$ for 16 hours. The hybridized slides were washed using 539 Gene Expression Wash Buffer 1 (Agilent Technologies, Part Number 5188-5325) and Gene 540 Expression Wash Buffer 2 (Agilent Technologies, Part Number 5188-5326) and were scanned 541 using Agilent Scanner (Agilent Technologies, Part Number G2600D). Data extraction from the 542 images was done using Feature Extraction Software Version 11.5.1.1 of Agilent.

543 Microarray data analysis

544 Microarray data analysis was undertaken by in-house coded R Script (https://cran.r545 project.org/). Processing of raw data into expression profiles was achieved by utilizing the 546 packages limma and affy. Probe intensities were converted into expression measures by standard 547 procedures. Briefly, the design-sets depicting the "control/test" arrays were carefully generated by 548 reading the raw data from MA image files. Background correction was done by the method 549 "normexp". This data was quantile normalized (between arrays depending on the design set), and 
550 within-array replicates were averaged. Processed data were categorized into major functional

551 categories and tabulated. The detailed microarray array discussed in this manuscript have been

552 deposited in GEO with accession number GSE154618.

553

554

\section{References}

555

556

557

558

559

560

561

562

563

564

565

566

567

568

569

570

571

Baba T, Ara T, Hasegawa M, Takai Y, Okumura Y, Baba M, Datsenko KA, Tomita M, Wanner BL, Mori, H. 2006. Construction of Escherichia coli K-12 in-frame, single-gene knockout mutants: The Keio collection. Molecular Systems Biology 2:2006.0008. DOI: https://doi.org/10.1038/msb4100050

Balasundaram D, Tabor C, Tabor H. 1993. Oxygen toxicity in a polyamine-depleted spe2A mutant of Saccharomyces cerevisiae. Proceedings of the National Academy of Sciences of the United States of America 90:4693-4697. DOI: https://doi.org/10.1073/pnas.90.10.4693

Benov L. 2001. How superoxide radical damages the cell. Protoplasma 217:33-36. DOI: https://doi.org/10.1007/BF01289410

Bleeke T, Zhang H, Madamanchi N, Patterson C, Faber JE. 2004. Catecholamine-Induced Vascular Wall Growth is Dependent on Generation of Reactive Oxygen Species. Circulation Research 94:37-45. DOI:

https://doi.org/10.1161/01.RES.0000109412.80157.7D

Casero RA, Murray Stewart T, Pegg AE. 2018. Polyamine metabolism and cancer: treatments, challenges and opportunities. Nature Reviews Cancer 18:681-695. DOI: https://doi.org/10.1038/s41568-018-0050-3

Chattopadhyay MK, Tabor CW, Tabor H. 2003. Polyamines protect Escherichia coli cells from 
the toxic effect of oxygen. Proceedings of the National Academy of Sciences of the United States of America 100:2261-2265. DOI: https://doi.org/10.1073/pnas.2627990100

Chattopadhyay MK, Tabor CW, Tabor H. 2006. Polyamine deficiency leads to accumulation of reactive oxygen species in a spe2 $\triangle$ mutant of Saccharomyces cerevisiae. Yeast 23:751-761. DOI: https://doi.org/10.1002/yea.1393

Chen J, Rogers SC, Kavdia M. 2013. Analysis of kinetics of dihydroethidium fluorescence with superoxide using xanthine oxidase and hypoxanthine assay. Annals of Biomedical Engineering 41:327-337. DOI: https://doi.org/10.1007/s10439-012-0653-x

Datsenko KA, Wanner BL. 2000. One-step inactivation of chromosomal genes I Escherichia coli K-12 using PCR products. Proceedings of the National Academy of Sciences of the United States of America 97:6640-6645. DOI: https://doi.org/10.1073/pnas.120163297

Eisenberg T, Knauer H, Schauer A, Büttner S, Ruckenstuhl C, Carmona-Gutierrez D, Ring J, Schroeder S, Magnes C, Antonacci L, Fussi H, Deszcz L, Hartl R, Schraml E, Criollo A, Megalou E, Weiskopf D, Laun P, Heeren G, Breitenbach M, et al. 2009. Induction of autophagy by spermidine promotes longevity. Nature Cell Biology 11:1305-1314. DOI: https://doi.org/10.1038/ncb1975

Franco R, Panayiotidis MI, Cidlowski JA. 2007. Glutathione depletion is necessary for apoptosis in lymphoid cells independent of reactive oxygen species formation. Journal of Biological Chemistry 282:30452-30465. DOI: https://doi.org/10.1074/jbc.M703091200

Fridovich I. 1986. Biological effects of the superoxide radical. Archives of Biochemistry and Biophysics 247:1-11. DOI: https://doi.org/10.1016/0003-9861(86)90526-6 
Fujikawa M, Kobayashi K, Tsutsui Y, Tanaka T, Kozawa T. 2017. Rational Tuning of Superoxide Sensitivity in SoxR, the [2Fe-2S] Transcription Factor: Implications of SpeciesSpecific Lysine Residues. Biochemistry 56:403-410. DOI: https://doi.org/10.1021/acs.biochem.6b01096

Gardner PR, Fridovich I. 1992. Inactivation-reactivation of aconitase in Escherichia coli. A sensitive measure of superoxide radical. Journal of Biological Chemistry 267:8757-8763.

Gawlitta W, Stockem W, Weber K. 1981. Visualization of actin polymerization and depolymerization cycles during polyamine-induced cytokinesis in living Amoeba proteus. Cell and Tissue Research 215:249-261. DOI: https://doi.org/10.1007/BF00239112

Ha HC, Sirisoma NS, Kuppusamy P, Zweier JL, Woster PM, Casero RA. 1998a. The natural polyamine spermine functions directly as a free radical scavenger. Proceedings of the National Academy of Sciences of the United States of America 95:11140-11145. DOI: https://doi.org/10.1073/pnas.95.19.11140

Ha HC, Yager JD, Woster PA, Casero RA. 1998b. Structural specificity of polyamines and polyamine analogues in the protection of DNA from strand breaks induced by reactive oxygen species. Biochemical and Biophysical Research Communications 244:298-303. DOI: https://doi.org/10.1006/bbrc.1998.8258

Hammer ND, Skaar EP. 2011. Molecular mechanisms of Staphylococcus aureus iron acquisition. Annual Review of Microbiology 65:129-147. DOI: https://doi.org/10.1146/annurev-micro090110-102851

Hidalgo E, Demple B. 1994. An iron-sulfur center essential for transcriptional activation by the redox-sensing SoxR protein. EMBO Journal 13:138-146. DOI: 
https://doi.org/10.1002/j.1460-2075.1994.tb06243.x

616

617

618

619

620

621

622

623

624

625

626

627

628

629

630

631

632

633

634

635

636

Highlander SK, Hultén KG, Qin X, Jiang H, Yerrapragada S, Mason EO, Shang Y, Tiffany MW, Fortunov RM, Liu Y, Igboeli O, Petrosino J, Tirumalai M, Uzman A, Fox GE, Cardenas AM, Muzny DM, Hemphill L, Ding Y, Dugan S. 2007. Subtle genetic changes enhance virulence of methicillin resistant and sensitive Staphylococcus aureus. BMC Microbiology 7:99. DOI: https://doi.org/10.1186/1471-2180-7-99

Igarashi K, Kashiwagi K. 2000. Polyamines: Mysterious modulators of cellular functions. Biochemical and Biophysical Research Communications 271:559-564. DOI: https://doi.org/10.1006/bbrc.2000.2601

Imlay JA. 2008. Cellular defenses against superoxide and hydrogen peroxide. Annual Review of Biochemistry 77:755-776. DOI: https://doi.org/10.1146/annurev.biochem.77.061606.161055

Joshi G. 2012. ACME encoded speG abrogates the unique hypersensitivity of Staphylococcus aureus to exogenous polyami. Molecular Microbiology 82:9-20. DOI: https://doi.org/10.1111/j.1365-2958.2011.07809.x.ACME

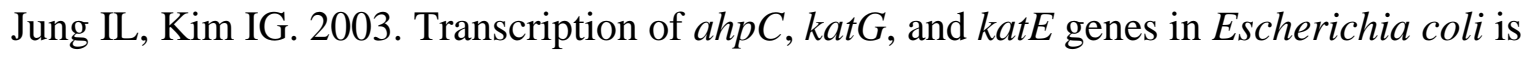
regulated by polyamines: Polyamine-deficient mutant sensitive to $\mathrm{H}_{2} \mathrm{O}_{2}$-induced oxidative damage. Biochemical and Biophysical Research Communications 301:915-922. DOI: https://doi.org/10.1016/S0006-291X(03)00064-0

Kalyanaraman B, Darley-Usmar V, Davies KJA, Dennery PA, Forman HJ, Grisham MB, Mann GE, Moore K, Roberts $2^{\text {nd }}$ LJ, Ischiropoulos H. 2012. Measuring reactive oxygen and nitrogen species with fluorescent probes: Challenges and limitations. Free Radical Biology 
and Medicine 52:1-6. DOI: https://doi.org/10.1016/j.freeradbiomed.2011.09.030

638

639

640

641

642

643

644

645

646

647

648

649

650

651

652

653

654

655

656

657

658

Kaur G, Sengupta S, Kumar V, Kumari A, Ghosh A, Parrack P, Dutta D. 2014. Novel MntRIndependent mechanism of manganese homeostasis in Escherichia coli by the ribosomeassociated protein HflX. Journal of Bacteriology 196:2587-2597. DOI: https://doi.org/10.1128/JB.01717-14

Kaur G, Kumar V, Arora A, Tomar A, Ashish, Sur R, Dutta D. 2017. Affected energy metabolism under manganese stress governs cellular toxicity. Scientific Reports 7:11645 DOI: https://doi.org/10.1038/s41598-017-12004-3

Khan AU, Di Mascio P, Medeiros MHG, Wilson T. 1992a. Spermine and spermidine protection of plasmid DNA against single-strand breaks induced by singlet oxygen. Proceedings of the National Academy of Sciences of the United States of America 89:11428-11430. DOI: https://doi.org/10.1073/pnas.89.23.11428

Khan AU, Mei YH, Wilson T. 1992b. A proposed function for spermine and spermidine: Protection of replicating DNA against damage by singlet oxygen. Proceedings of the National Academy of Sciences of the United States of America 89:11426-11427. DOI: https://doi.org/10.1073/pnas.89.23.11426

Kobayashi K. 2017. Sensing Mechanisms in the Redox-Regulated, [2Fe-2S] Cluster-Containing, Bacterial Transcriptional Factor SoxR. Accounts of Chemical Research 50:1672-1678. DOI: https://doi.org/10.1021/acs.accounts.7b00137

Koo MS, Lee JH, Rah SY, Yeo WS, Lee JW, Lee KL, Koh YS, Kang SO, Roe JH. 2003. A reducing system of the superoxide sensor SoxR in Escherichia coli. EMBO Journal, 22:2614-2622. DOI: https://doi.org/10.1093/emboj/cdg252 
Kreiswirth BN, Löfdahl S, Betley MJ, O’reilly M, Schlievert PM, Bergdoll MS, Novick RP. 1983. The toxic shock syndrome exotoxin structural gene is not detectably transmitted by a prophage. Nature 305:709-712. DOI: https://doi.org/10.1038/305709a0

Kwon DH, Lu, CD. 2007. Polyamine effects on antibiotic susceptibility in bacteria. Antimicrobial Agents and Chemotherapy 51:2070-2077. DOI: https://doi.org/10.1128/AAC.01472-06

Limsuwun K, Jones PG. 2000. Spermidine acetyltransferase is required to prevent spermidine toxicity at low temperatures in Escherichia coli. J. Bacteriol 182:5373-5380. DOI:10.1128/JB.182.19.5373-5380.2000

Liochev S, Fridovich I. 2011. Is superoxide able to induce SoxRS? Free Radical Biology and Medicine 50:1813 DOI: https://doi.org/10.1016/j.freeradbiomed.2011.03.029

Lo FC, Lee, JF, Liaw WF, Hsu IJ, Tsai YF, Chan SI, Yu SSF. 2012. The Metal Core Structures in the Recombinant Escherichia coli Transcriptional Factor SoxR. Chemistry - A European Journal 18:2565-2577. DOI: https://doi.org/10.1002/chem.201100838

LØVaas E. 1996. Antioxidative and Metal-Chelating Effects of Polyamines. Advances in Pharmacology 38:119-149. DOI: https://doi.org/10.1016/S1054-3589(08)60982-5

Madeo F, Eisenberg T, Pietrocola F, Kroemer G. 2018. Spermidine in health and disease. Science 359:aan2788 DOI: https://doi.org/10.1126/science.aan2788

Martin E, Waters LS, Storz G, Imlay JA. 2015. The Escherichia coli Small Protein MntS and Exporter MntP Optimize the Intracellular Concentration of Manganese. PLOS Genetics 11:e1004977. DOI: https://doi.org/10.1371/journal.pgen.1004977 
680

681

682

683

684

685

686

687

688

689

690

691

692

693

694

695

696

697

698

699

700

Michael AJ. 2018. Polyamine function in archaea and bacteria. Journal of Biological Chemistry 293:18693-18701. DOI: https://doi.org/10.1074/jbc.TM118.005670

Miller-Fleming L, Olin-Sandoval V, Campbell K, Ralser M. 2015. Remaining Mysteries of Molecular Biology: The Role of Polyamines in the Cell. Journal of Molecular Biology 427:3389-3406. DOI: https://doi.org/10.1016/j.jmb.2015.06.020

Miyamoto S, Kashiwagi K, Ito K, Watanabe SI, Igarashi K. 1993. Estimation of Polyamine Distribution and Polyamine Stimulation of Protein Synthesis in Escherichia coli. Archives of Biochemistry and Biophysics 300:63-68. DOI: https://doi.org/10.1006/abbi.1993.1009

Nimse SB, Pal D. 2015. Free radicals, natural antioxidants, and their reaction mechanisms. RSC Advances 5:27986-28006. DOI: https://doi.org/10.1039/c4ra13315c

Olavarría K, Valdés D, Cabrera R. 2012. The cofactor preference of glucose-6-phosphate dehydrogenase from Escherichia coli- modeling the physiological production of reduced cofactors. FEBS Journal 279:2296-2309. DOI: https://doi.org/10.1111/j.17424658.2012.08610.x

Oriol-Audit C. 1978. Polyamine-Induced Actin Polymerization. European Journal of Biochemistry 82:371-376. DOI: https://doi.org/10.1111/j.1432-1033.1978.tb12386.x

Pegg AE. 2013. Toxicity of polyamines and their metabolic products. Chemical Research in Toxicology 26:1782-1800. DOI: 10.1021/tx400316s

Pegg AE. 2016. Functions of polyamines in mammals. Journal of Biological Chemistry 291:14904-14912.DOI: https://doi.org/10.1074/jbc.R116.731661

Pegg AE. 2018. Introduction to the thematic minireview series: Sixty plus years of polyamine 
research. Journal of Biological Chemistry 293:18681-18692. DOI:

https://doi.org/10.1074/jbc.TM118.006291

Pohjanpelto P, Virtanen I, Hölttä E. 1981. Polyamine starvation causes disappearance of actin filaments and microtubules in polyamine-auxotrophic CHO cells. Nature 293:475-477. DOI: https://doi.org/10.1038/293475a0

Sandoval JM, Arenas FA, Vásquez CC. 2011. Glucose-6-Phosphate Dehydrogenase Protects Escherichia coli from Tellurite-Mediated Oxidative Stress. PLoS ONE 6:e25573. DOI: https://doi.org/10.1371/journal.pone.0025573

Schuber F. 1989. Influence of polyamines on membrane functions. Biochemical Journal, 260:110. DOI: https://doi.org/10.1042/bj2600001

Schwartz CJ, Giel JL, Patschkowski T, Luther C, Ruzicka FJ, Beinert H, Kiley PJ. 2001. IscR, an Fe-S cluster-containing transcription factor, represses expression of Escherichia coli genes encoding Fe-S cluster assembly proteins. Proceedings of the National Academy of Sciences of the United States of America 98:14895-14900. DOI: https://doi.org/10.1073/pnas.251550898

Stewart TM, Dunston TT, Woster PM, Casero RA. 2018. Polyamine catabolism and oxidative damage. Journal of Biological Chemistry 293:18736-18745. DOI: https://doi.org/10.1074/jbc.TM118.003337

Stieglmeier M, Wirth R, Kminek G, Moissl-Eichinger C. 2009. Cultivation of anaerobic and facultatively anaerobic bacteria from spacecraft-associated clean rooms. Applied and Environmental Microbiology 75:3484-3491. DOI: https://doi.org/10.1128/AEM.02565-08 
722

723

724

725

726

727

728

729

730

731

732

733

734

735

736

737

738

739

740

741

742

Sun SY. 2010. N-acetylcysteine, reactive oxygen species and beyond. Cancer Biology and

Therapy 9:109-110. DOI: https://doi.org/10.4161/cbt.9.2.10583

Tabor CW, Tabor H. 1984. Polyamines. Annual Review of Biochemistry 53:749-790.

https://doi.org/10.1146/annurev.bi.53.070184.003533

Tadolini B. 1988a. Polyamine inhibition of lipoperoxidation. The influence of polyamines on iron oxidation in the presence of compounds mimicking phospholipid polar heads. The Biochemical Journal 249:33-36. DOI: https://doi.org/10.1042/bj2490033

Tadolini B. 1988b. The influence of polyamine-nucleic acid complexes on $\mathrm{Fe}^{2+}$ autoxidation. Molecular and Cellular Biochemistry 83:179-185. DOI:

https://doi.org/10.1007/BF00226145

Tang Y, Quail MA, Artymiuk PJ, Guest JR. Green J. 2002. Escherichia coli aconitases and oxidative stress: Post-transcriptional regulation of sodA expression. Microbiology 148: 1027-1037. DOI: https://doi.org/10.1099/00221287-148-4-1027

Touati D. 2000. Sensing and protecting against superoxide stress in Escherichia coli - How many ways are there to trigger soxRS response? Redox Report 5:287-293. DOI: https://doi.org/10.1179/135100000101535825

Wallace HM, Fraser AV, Hughes A. 2003, A perspective of polyamine metabolism. Biochemical Journal 376:1-14. DOI: https://doi.org/10.1042/BJ20031327

Waller JC, Alvarez S, Naponelli V, Lara-Nuñez A, Blaby IK, Da Silva V, Ziemak MJ, Vickers TJ, Beverly SM, Edison S, Rocca JR, Gregory $3^{\text {rd } J F, ~ d e ~ C r e c y-L a g a r d ~ V, ~ H a n s o n ~ A D . ~}$ 2010. A role for tetrahydrofolates in the metabolism of iron-sulfur clusters in all domains of 
life. Proceedings of the National Academy of Sciences of the United States of America 107:10412-10417. DOI: https://doi.org/10.1073/pnas.0911586107

Waters LS, Sandoval M, Storz G. 2011. The Escherichia coli MntR miniregulon includes genes encoding a small protein and an efflux pump required for manganese homeostasis. Journal of Bacteriology 193:5887-5897. DOI: https://doi.org/10.1128/JB.05872-11

Wu J, Weiss B. 1992. Two-stage induction of the soxRS (superoxide response) regulon of Escherichia coli. Journal of Bacteriology 174:3915-3920. DOI: https://doi.org/10.1128/jb.174.12.3915-3920.1992

Yao X, Lu CD. 2014. Characterization of Staphylococcus aureus Responses to Spermine Stress. Current Microbiology 69:394-403. DOI: https://doi.org/10.1007/s00284-014-0603-y

Zaslaver A, Bren A, Ronen M, Itzkovitz S, Kikoin I, Shavit S, Liebermeister W, Surette MG, Alon U. 2006. A comprehensive library of fluorescent transcriptional reporters for Escherichia coli. Nature Methods 8:623-628. DOI: https://doi.org/10.1038/nmeth895

\section{Acknowledgements}

The authors are grateful to Dr. Debashish Adhikari, Division of Chemical Sciences, IISER Mohali, for their critical inputs on the plausible binding mechanism of spermidine and iron. The work has been funded by CSIR IMTECH, India to DD. VK was an ICMR fellow, RKM is a UGC fellow, DG is a CSIR fellow, AK is a DST-Inspire fellow, and AP is a DBT fellow.

\section{Author Contributions}

VK, RKM, DG, AK and AP performed the experiments and discussed the data with DD. AA analyzed microarray gene expression raw data. GM analyzed data for ITC, bipyridyl and NBT 
765 assays to figure our coordination complex formation. AA and GM provided critical inputs to

766 enhance the quality of work. DD conceptualized the work, analyzed the data and wrote the

767 manuscript.

768 Competing Interests

769 The authors declare no competing interests.

770 Data Availability

771 All data are available in the main text, the supplementary files and source data.

772

773

774

775

776

777

778

779

780

781

782

783

784 
785 Table 1. The list of strains and plasmids used in this work

\begin{tabular}{lll}
\hline Strains and & Genotype/Features & References \\
plasmids & & \\
\hline
\end{tabular}

\section{Strains}

BW25113

Escherichia coli; rrnB3 $\Delta l a c Z 4787$ hsdR514

(Baba et al., 2006)

$\Delta(\operatorname{araBAD}) 567 \Delta(r h a B A D) 568 r p h-1$

S. aureus RN4220 NCTC8325-4; mutation in saul hsdR

(Kreiswirth et al., 1983)

S. aureus USA300

Staphylococcus aureus subsp. aureus

(Kreiswirth et al.,

Rosenbach ATCC BAA-1717

$\Delta \operatorname{spe} G$

BW25113, $\Delta$ speG $: k_{k a n}{ }^{R}$

(Baba et al., 2006)

$\Delta \operatorname{sod} A$

BW25113, $\Delta \operatorname{sodA}: k_{k a n}{ }^{R}$

(Baba et al., 2006)

$\Delta \operatorname{sod} B$

BW25113, $\Delta$ sodB $: k_{k a n}^{R}$

(Baba et al., 2006)

$\Delta z w f$

BW25113, $\Delta$ sodC $: k_{k a n}{ }^{R}$

(Baba et al., 2006)

$\Delta$ fis

BW25113, $\Delta$ fis::kan ${ }^{R}$

(Baba et al., 2006)

$\triangle i h f A$

BW25113, $\Delta i h f A:: k_{a n}^{R}$

(Baba et al., 2006)

$\Delta i s c U$

BW25113, $\Delta i s c U: k_{k a n}{ }^{R}$

(Baba et al., 2006)

$\Delta y g f Z$

BW25113, $\Delta y g f Z:: k a n^{R}$

(Baba et al., 2006)

$\Delta$ soxS

BW25113, $\Delta$ soxS::kan ${ }^{R}$

(Baba et al., 2006)

$\triangle \operatorname{mar} A$

BW25113, $\Delta$ marA $: k_{k a n}^{R}$

(Baba et al., 2006)

$\Delta m a r B$

BW25113, $\Delta$ marB $: k_{k a n}^{R}$

(Baba et al., 2006)

$\triangle a h p C$

BW25113, $\Delta a h p C:: k a n^{R}$

(Baba et al., 2006)

$\Delta k a t G$

BW25113, $\Delta k a t G:: k a n^{R}$

(Baba et al., 2006)

$\triangle \operatorname{spe} G \Delta \operatorname{sod} A$

BW25113, $\Delta$ speG, $\Delta$ sodA $: k_{k a n}^{R}$

This study

$\Delta \operatorname{spe} G \Delta \operatorname{sodB}$

BW25113, $\Delta$ speG, $\Delta$ sodB $: k_{k a n}{ }^{R}$

This study

$\Delta \operatorname{spe} G \Delta \operatorname{sod} A \Delta \operatorname{sod} B$

BW25113, $\Delta$ speG, $\Delta$ sodA, $\Delta \operatorname{sodB}:: k^{2} n^{R}$

This study

$\Delta s p e G \Delta z w f$

BW25113, $\Delta$ spe $G, \Delta z w f:: k a n^{R}$

This study

$\Delta$ speG $\Delta$ soxS

BW25113, $\Delta$ speG, $\Delta$ soxS $: k_{k a n}^{R}$

This study 


\begin{tabular}{|c|c|c|}
\hline$\Delta$ speG $\Delta$ fis & $\mathrm{BW} 25113, \Delta$ spe $G, \Delta$ fis $: k_{a n}^{R}$ & This study \\
\hline$\Delta s p e G \Delta i h f A$ & BW25113, $\Delta$ spe $G, \Delta i h f A:: k a n^{R}$ & This study \\
\hline$\Delta s p e G \Delta i s c U$ & BW25113, $\Delta$ spe $G, \Delta i s c U \because k_{a n}{ }^{R}$ & This study \\
\hline$\Delta s p e G \Delta y g f Z$ & BW25113, $\Delta$ spe $G, \Delta y g f Z:: k a n^{R}$ & This study \\
\hline$\Delta s p e G \Delta m a r A$ & $\mathrm{BW} 25113, \Delta \operatorname{spe} G, \Delta \operatorname{mar} A:: k a n^{R}$ & This study \\
\hline$\Delta s p e G \Delta$ marB & $\mathrm{BW} 25113, \Delta \operatorname{spe} G, \Delta \operatorname{marB}:: k a n^{R}$ & This study \\
\hline JRG3533 & MC4100 ф(sodA-lacZ)49, $\mathrm{cm}^{\mathrm{R}}$ & (Tang et al., 2002) \\
\hline RKM1 & $\mathrm{BW} 25113, \Delta$ speG, sodA-lacZ: $\mathrm{cm}^{\mathrm{R}}$ & This study \\
\hline \multicolumn{3}{|l|}{ Plasmids } \\
\hline pET28a (+) & $k_{a n}^{R}$; T7-promoter; IPTG inducible & Novagen \\
\hline pBAD/Myc-His A & $a m p^{R} ;$ pBAD-promoter; Ara inducible & ThermoFisher \\
\hline pBAD-zwf & $z w f$ cloned in pBAD TOPO (Invitrogen) & $\begin{array}{l}\text { (Sandoval et } \\
\text { al.,2011) }\end{array}$ \\
\hline pBAD-sodA & sodA cloned in $\mathrm{pBAD} / \mathrm{Myc}-\mathrm{His} \mathrm{A}$ vector & This study \\
\hline pET-sodA & sodA cloned in pET28a (+) vector & This study \\
\hline pET-ahpC & $a h p C$ cloned in pET28a $(+)$ vector & This study \\
\hline pET-katG & $k a t G$ cloned in pET28a (+) vector & This study \\
\hline pBAD-spe $G$ & spe $G$ cloned in $\mathrm{pBAD} / \mathrm{Myc}-\mathrm{His} \mathrm{A}$ vector & This study \\
\hline pUA66_soxS & $\begin{array}{l}\mathrm{kan}^{R} ; \text { soxS promoter cloned upstream of } \\
\text { gfpmut } 2 \text { reporter in pUA66 }\end{array}$ & $\begin{array}{l}\text { (Zaslaver et al., } \\
\text { 2006) }\end{array}$ \\
\hline pUA66_ahpC & $\begin{array}{l}\mathrm{kan}^{R} ; \text { ahpC promoter cloned upstream of } \\
\text { gfpmut2 reporter in pUA66 }\end{array}$ & $\begin{array}{l}\text { (Zaslaver et al., } \\
\text { 2006) }\end{array}$ \\
\hline pUA66_katG & $\begin{array}{l}k a n^{R} ; k a t G \text { promoter cloned upstream of } \\
\text { gfpmut2 reporter in pUA66 }\end{array}$ & $\begin{array}{l}\text { (Zaslaver et al., } \\
\text { 2006) }\end{array}$ \\
\hline $\begin{array}{l}\text { NOTE: } \operatorname{kan}^{R}, \text { kan } \\
\text { chloramphenicol I }\end{array}$ & $\begin{array}{l}\text { in resistance; } a m p^{R} \text {, ampicillin resistanc } \\
\text { ance. }\end{array}$ & $\mathrm{cm}^{R}$ \\
\hline
\end{tabular}


A. The relative MFI values for the H2DCFDA, which is an indicator of $\bullet \mathrm{OH}$ radical production, obtained by flow cytometry analyses are plotted. B. The relative MFI values of DHE probe, which is an indicator of $\mathrm{O}_{2}^{-}$radical production, obtained by flow cytometry analyses are plotted. $\mathbf{C}$. The absolute $\mathrm{H}_{2} \mathrm{O}_{2}$ production for a span of 5 hours from the different E. coli strains are shown. *** are $\mathrm{P}$ values generated comparing with WT value. D. ZOIs surrounding SPD well on the agar plates were shown for the WT and $\Delta$ spe $G$ strains of $E$. coli under aerobic and anaerobic conditions. E. Serially diluted E. coli cells were spotted on LB-agar plates to show their sensitivity to SPD. F. Viability of different knockout strains were plotted from the CFU counts in different time intervals after treatment with lethal dose of SPD. $* *$ and $* * *$ are $\mathrm{P}$ values generated comparing with the values of $\Delta s p e G$ and $\Delta$ speG $\Delta \operatorname{sod} A$, respectively. Error bars in the panels are mean \pm SD from the three independent experiments. Whenever mentioned, *** and ** are $<0.001$ and $<0.01$, respectively; unpaired T test. See also Figure 1 - figure supplement 1, and source data 1-4. of SpeG function

A and $\mathbf{B}$ represents the growth curves of $E$. coli WT and $\Delta s p e G$ strains, respectively, in the that single $\Delta \operatorname{sod} A$ and $\Delta \operatorname{sod} B$ mutants are not affected by SPD.

Source data 2- Figure $1 \mathrm{~B}$ raw data

\section{Figure 2. $\mathrm{O}_{2}^{-}$and other intracellular $\mathrm{ROS}$ production in $\mathrm{S}$. aureus}

A. The bar diagram shows normalized MFI of DHE fluorescence, as a function of $\mathrm{O}_{2}^{-}$radical levels in S. aureus RN4220 and USA300 in the presence or absence of SPD. B. ZOI surrounding SPD well on the agar plate was determined for the S. aureus (S.a.) and USA300 strains under aerobic and anaerobic conditions. C. The bar diagram shows normalized MFI of H2DCFDA fluorescence DHE fluorescence, as a function of $\bullet \mathrm{OH}$ radical levels in S. aureus RN4220 and USA300 in the presence or absence of SPD. D. The plot shows $\mathrm{H}_{2} \mathrm{O}_{2}$ production from $S$. aureus strains in the 
SD from the three independent experiments. $* *$ and $* * *$ denote $\mathrm{P}$ values $<0.01<001$; unpaired $\mathrm{T}$ test. See also source data 5 and 6.

Source data 5- Figure $2 \mathrm{~A}$ and $2 \mathrm{C}$ raw data

Source data 6- Figure 2D raw data

Figure 3. $\mathrm{O}_{2}^{-}$radical production affects redox balance in the spermidine-fed $\Delta s p e G$ strain.

A. Growth curves show that Tiron (Tr), Ascorbate (Asc) and N-acetyl cysteine (NAC) can overcome spermidine (SPD) stress while sodium pyruvate (SP) and Thiourea (TU) fails to do so. B. Growth curves show that $\Delta s p e G \Delta z w f$ strain is hypersensitive to SPD in comparison to $\Delta s p e G$ strain. Complementation of $\Delta s p e G \Delta z w f$ strain with pZwf plasmid overcomes this SPD hypersensitivity. C. CFUs were obtained for different E. coli strains pretreated with SPD for desired time points and plotted to show the reduced viability of $\Delta s p e G \Delta z w f$ strain in comparison to the $\Delta$ spe $G$ strain. D. Relative levels of NADPt and NADPH were significantly decreased in the $\Delta s p e G$ strain under SPD stress. E. Relative levels of GSt, GSH and GSSG were significantly decreased in the SPD-fed $\Delta s p e G$ strain. F. No significant change in the relative total NAD (NADt), $\mathrm{NAD}+$ and NADH levels were recorded. However, NAD+ to NADH ratio was significantly increased in the $\Delta s p e G$ strain compared to WT cells. No further increase of the ratio was observed by adding SPD in the growth medium of WT and $\Delta s p e G$ strain. G. The relative level of ATP was declined in $\Delta$ speG strain and spermidine-fed WT cells in comparison to the unfed WT. SPD supplementation decreased the ATP level further in the SPD-fed $\Delta$ spe $G$ strain. Error bars in the panels are mean \pm SD from the three independent experiments. Whenever mentioned, the $* * *$ and ** denote $\mathrm{P}$ values $<0.001$ and $<0.01$, respectively; unpaired $\mathrm{T}$ test. See also source data $7-11$.

Source data 7- Figure $3 \mathrm{~A}$ raw data

Source data 8- Figure 3B raw data

Source data 9- Figure $3 \mathrm{C}$ raw data

Source data 10- Figure 3D, 3E and 3F raw data

Source data 11- Figure $3 \mathrm{G}$ raw data 

metabolism.

851

852

853

854

855

856

857

858

859

860

861

862

863

864

865

866

867

868

869

870

871

872

873

874

875

876

877

878

A. (i) Microarray heat map showing various categories of genes (categories: I-IX; see Supplementary file 1) that were differentially expressed under spermidine stress. (ii) Zoomed in heat-map of the category II genes responsible for iron metabolism and ROS regulation (iii) Color key represents the expression fold-change of the genes.

B. The subpanel (i) represents a flow cytometry experiment to demonstrate that spermidine (SPD) stress inhibits menadione (MD)induced $\mathrm{P}_{\text {soxs- }}$ gfpmut2 reporter fluorescence. The subpanel (ii) represents relative MFIs in the presence or absence of SPD and MD calculated from three different flow cytometry experiments. C, D, E. Western blotting experiments show SodA, KatG and AhpC levels in the various strains in the presence or absence of SPD; (i) developed blot, (ii) ponceau S-stained counterpart of the same blot, (iii) The bar diagrams represent relative fold change (FC) of the proteins under SPD stress. The relative FC values were calculated from the band intensity values obtained from three independent blots in comparison to the untreated WT counterparts. Purified 6X his-tagged SodA, KatG and AhpC proteins were loaded as positive controls. The cellular protein extracts from $\Delta \operatorname{sod} A, \Delta k a t G$ and $\Delta a h p C$ strains were used for negative controls. F. The bar diagram represents relative aconitase activity in the $E$. coli WT and $\Delta s p e G$ strains in the presence and absence of SPD. G. Intracellular levels of Fe and Mn levels for E. coli strains, and Fe levels for S. aureus strains determined in the presence or absence of SPD stress were plotted. H. Spot assay using serially diluted $\Delta$ spe $G$ cells demonstrated that $\mathrm{Fe}^{2+}$ can rescue SPD stress. I. Spot assay shows the relative

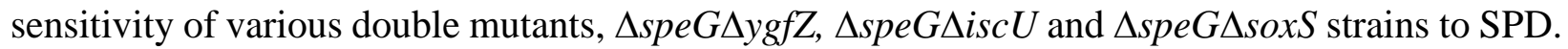
Error bars in the panels are mean \pm SD from the three independent experiments. Whenever mentioned, the ***, $* *$ and $*$ denote $\mathrm{P}$ values $<0.001,<0.01$ and $<0.1$ respectively; unpaired $\mathrm{T}$ test. See also Figure 4 - figure supplement 1, Figure 4 - figure supplement 2, and source data 12-16.

Figure 4 - figure supplement 1. Indication of the importance of Fis regulator under spermidine stress. The colonies of different mutant E. coli strains were steaked on the LB agar surface to show that $\Delta$ spe $G \Delta$ fis slow growing compared to $\Delta$ spe $G$ and $\Delta$ spe $G \Delta i h f A$ strains.

\section{Figure 4 - figure supplement 2. Validation of microarray data}

A. Microarray data was validated by performing RT-qPCR against some of the genes that were up or down-regulated in the Microarray 
B. RT-qPCR data to show that the spermidine stress does not alter the expression of soxS, sodA, and $z w f$ genes in the $\Delta s p e G$ strain. RT-qPCR data to show that the spermidine stress does not alter the expression of soxS, sodA, and zwf genes in the $\Delta$ spe $G$ strain.

882 C. Flow cytometry experiments determined that spermidine stress does not upregulate $\mathrm{P}_{\text {soxs }}{ }^{-}$ gfpmut 2 reporter in the $\Delta s p e G$ strain. The upper portion of the panel (i) represents a flow cytometry histogram. Grey area is background fluorescence of the $\Delta$ spe $G$ cells. The areas within saffron-line and blue-line represent GFP fluorescence in the absence and presence of spermidine, respectively. The bar diagram in the lower part of the panel (ii) exhibits relative MFI values calculated from three independent flow cytometry experiments.

D. $\beta$-galactosidase reporter assay shows that the promoter activity of sodA gene remains unchanged under spermidine stress.

E. Flow cytometry experiments were performed to show that spermidine stress does not upregulate $\mathrm{P}_{a h p C^{-}} g f p$ reporter in the $\Delta s p e G$ strain. The subpanel (i) represents a flow cytometry histogram of background fluorescence of the $\Delta s p e G$ cells (grey area). The pink-lined and green-lined areas of histogram represent fluorescence in the absence and presence of spermidine, respectively. The bar diagram in the subpanel (ii) exhibits relative MFI values calculated from three independent flow cytometry experiments.

F. Flow cytometry experiments show that spermidine stress downregulates $\mathrm{P}_{k a t G^{-}}$gfp reporter expression in the $\Delta s p e G$ strain. The subpanel (i) represents histogram of background fluorescence of the $\Delta$ spe $G$ cells (grey area). The green-lined and pink-lined areas of histogram represent GFP fluorescence in the absence and presence of spermidine, respectively. The bar diagram in the lower part of the panel (ii) exhibits relative MFI values in the presence or absence of spermidine calculated from three independent flow cytometry experiments. $* * *$ denotes $\mathrm{P}$ value $<0.001$; unpaired T-test.

904 Source data 13- Figure 4C, 4D and 4E full images for western blots

905 Source data 14- Figure 4C, 4D and 4E fold change values of the western blots

906 Source data 15- Figure 4F raw data

907 Source data 16- Figure $4 \mathrm{G}$ raw data 
Figure 5. Spermidine oxidizes $\mathrm{Fe}^{2+}$ generating $\mathrm{O}_{2}^{-}$radical in aerobic condition.

911

912

913

914

915

916

917

918

919

920

921

922

923

924

925

926

927

928

929

930

931

932

933

934

935

936

937

938

939

A. ITC data demonstrates the interaction of spermidine with $\mathrm{Fe}^{3+}$. $\mathbf{B}$ and $\mathbf{C}$. ITC data shows the interaction of spermidine with $\mathrm{Fe}^{2+}$ ion at $4^{\circ} \mathrm{C}$ and $25^{\circ} \mathrm{C}$, respectively. D. $100 \mu \mathrm{M}$ spermidine was incubated with different concentrations of $\mathrm{Fe}^{2+}$ followed by estimation of $\mathrm{Fe}^{2+}$ levels by bipyridyl chelator. The color formation was recorded at $522 \mathrm{~nm}$ and plotted them along with standard curve. The panel depicts that the incubations of $100 \mu \mathrm{M}$ spermidine with 100,200 and $300 \mu \mathrm{M}$ of $\mathrm{Fe}^{2+}$ in the anaerobic condition do not lead to the loss of $\mathrm{Fe}^{2+}$ ions detected by bipyridyl chelator. However, when $100 \mu \mathrm{M}$ spermidine was incubated with the different concentrations of $\mathrm{Fe}^{2+}(25$ $\mu \mathrm{M}$ to $350 \mu \mathrm{M})$ in the aerobic condition, the bipyridyl-mediated color formation was observed when $\mathrm{Fe}^{2+}$ level was between above $125 \mu \mathrm{M}$ to $150 \mu \mathrm{M}$ (i.e., till spermidine to $\mathrm{Fe}^{2+}$ ratio reaches approximately 1.3). The mean values from the three independent experiments were plotted. SD is negligible and is not shown for clarity. E. NBT assay was performed to determine that spermidine and $\mathrm{Fe}^{2+}$ interaction yields $\mathrm{O}_{2}^{-}$radical. The colorimetry at $575 \mathrm{~nm}$ suggests that $100 \mu \mathrm{M}$ of spermidine interacts approximately with $125 \mu \mathrm{M}$ of $\mathrm{Fe}^{2+}$ (ratio 1:1.3) to generate saturated color. Error bars in the panel are mean $\pm \mathrm{SD}$ from the three independent experiments. *** denotes $\mathrm{P}$ value $<0.001$; unpaired T test. F. Model to show final coordination complex formation. An $\mathrm{Fe}^{2+}$ interacts with two spermidine molecules forming hexadentate co-ordination complex. This interaction oxidizes $\mathrm{Fe}^{2+}$ liberating one electron to reduce oxygen molecule. Finally, two spermidine coordinates one $\mathrm{Fe}^{3+}$ with an octahedral geometry. G. The curves represent the E. coli total RNA inhibits iron oxidation. Spermidine further reduces the RNA- mediated iron oxidation at concentration $10 \mu \mathrm{M}$ but higher concentrations of spermidine increase the iron oxidation despite the presence of RNA. The mean values are derived from the three independent experiments and plotted. SD is negligible and is not shown for clarity. See also source data 17-19.

Source data 17- Figure 5D raw data

Source data 18- Figure 5E raw data

Source data 19- Figure $5 \mathrm{G}$ raw data

\section{Figure 6. Flow-chart explaining the ROS generation under spermidine stress}

The model describes that the spermidine administration in the cell interacts with free iron and oxygen to generate $\mathrm{O}_{2}^{-}$radical, increasing $\mathrm{Fe}^{3+} / \mathrm{Fe}^{2+}$ ratio. Spermidine also blocks $\mathrm{O}_{2}^{-}$radical- 
940 mediated activation of SoxRS that upregulates $z w f$ and sodA. Consequently, NADPH production

941 and dismutation of $\mathrm{O}_{2}^{-}$radical to $\mathrm{H}_{2} \mathrm{O}_{2}$ were not accelerated, leading to redox imbalance and $\mathrm{O}_{2}{ }^{-}$-

942 mediated damage to the iron-sulfur clusters, respectively. Additionally, spermidine translationally

943 upregulated alkyl hydroperoxidase $(\mathrm{AhpCF})$ that lowers the level of $\mathrm{H}_{2} \mathrm{O}_{2}$. Declined cellular $\mathrm{Fe}^{2+}$

944 and $\mathrm{H}_{2} \mathrm{O}_{2}$ levels weaken Fenton reaction to produce $\bullet \mathrm{OH}$ radical.

945

946 Supplementary file 1. Table listing microarray data representing upregulated (green) and 947 downregulated (red) genes

948

949 Supplementary file 2. Table listing the Fis and IHF regulated genes that were upregulated (green) 950 and downregulation (red).

951

952 Supplementary file 3. Table listing the oligonucleotide primers used in this study.

Figure 1 - figure supplement 1 - Spermidine-mediated $\mathrm{O}_{2}$ - production is toxic in the absence of SpeG function 
Figure 1

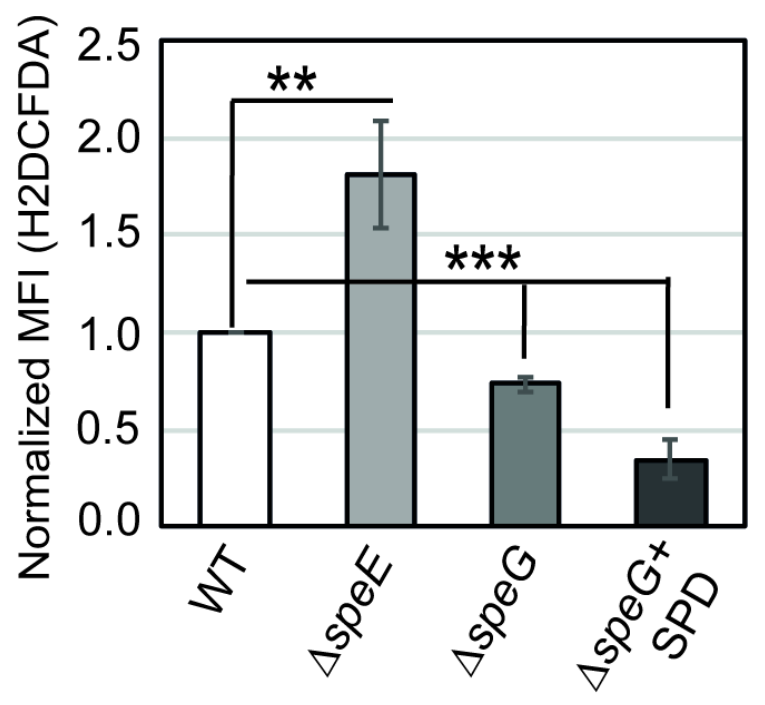

C.

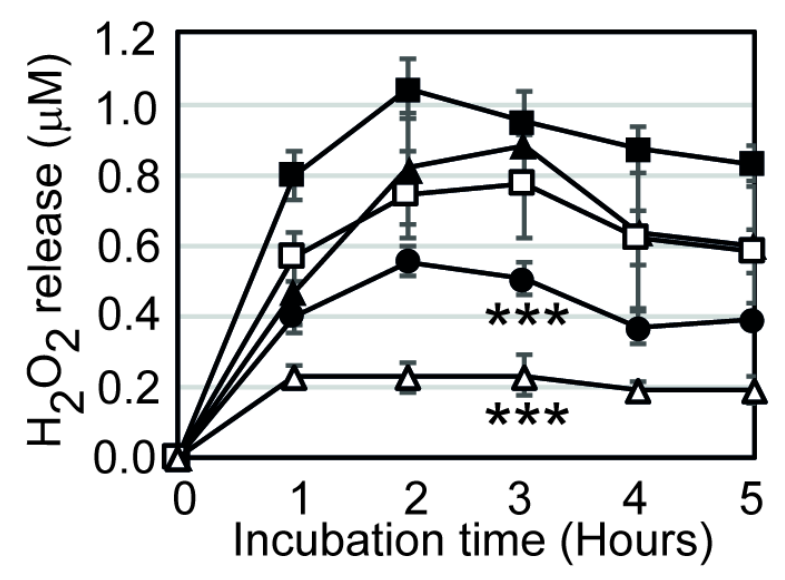

$\rightarrow-W T \rightarrow \Delta s p e E \simeq \Delta s p e G$

$\rightarrow-W T+S P D \rightarrow-\Delta s p e G+S P D$

E.

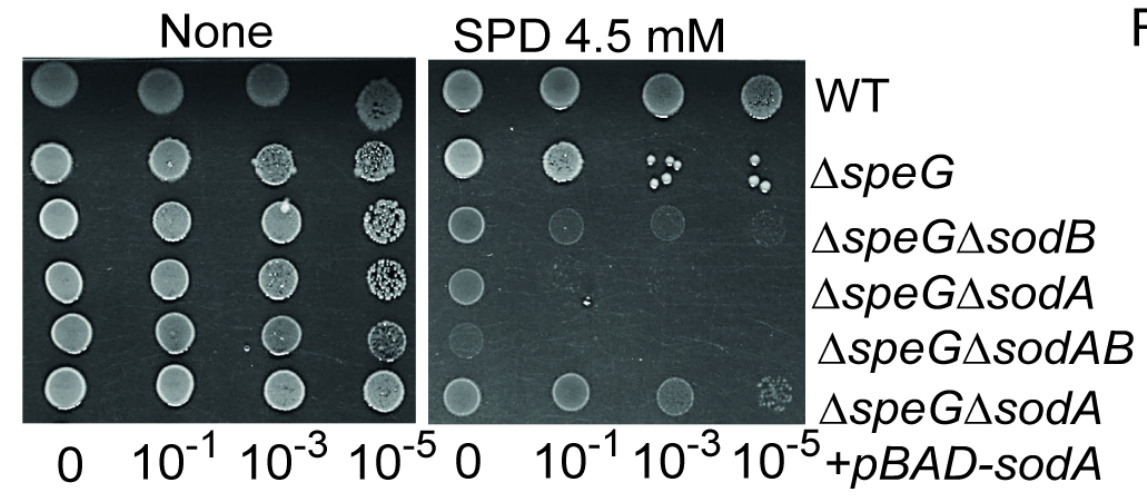

Dilutions
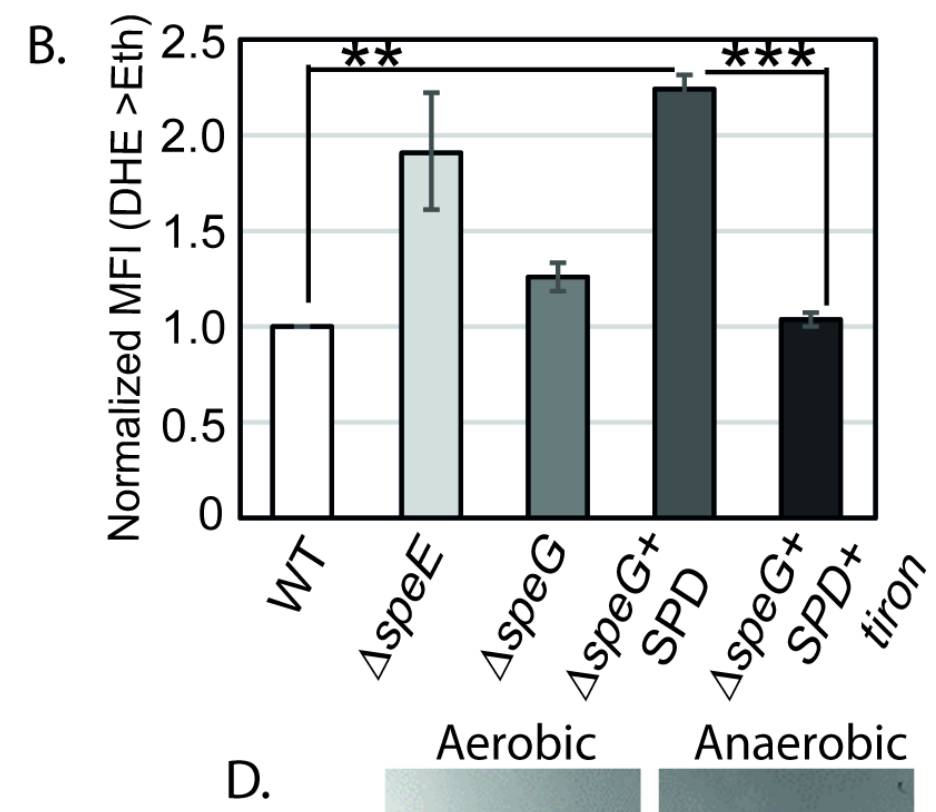

WT

$\Delta$ speG

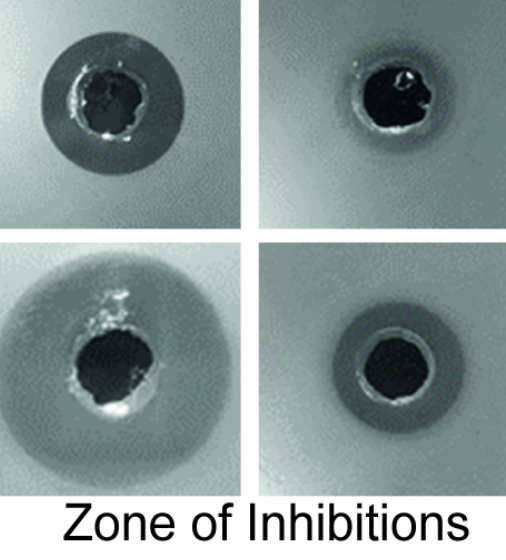

F.
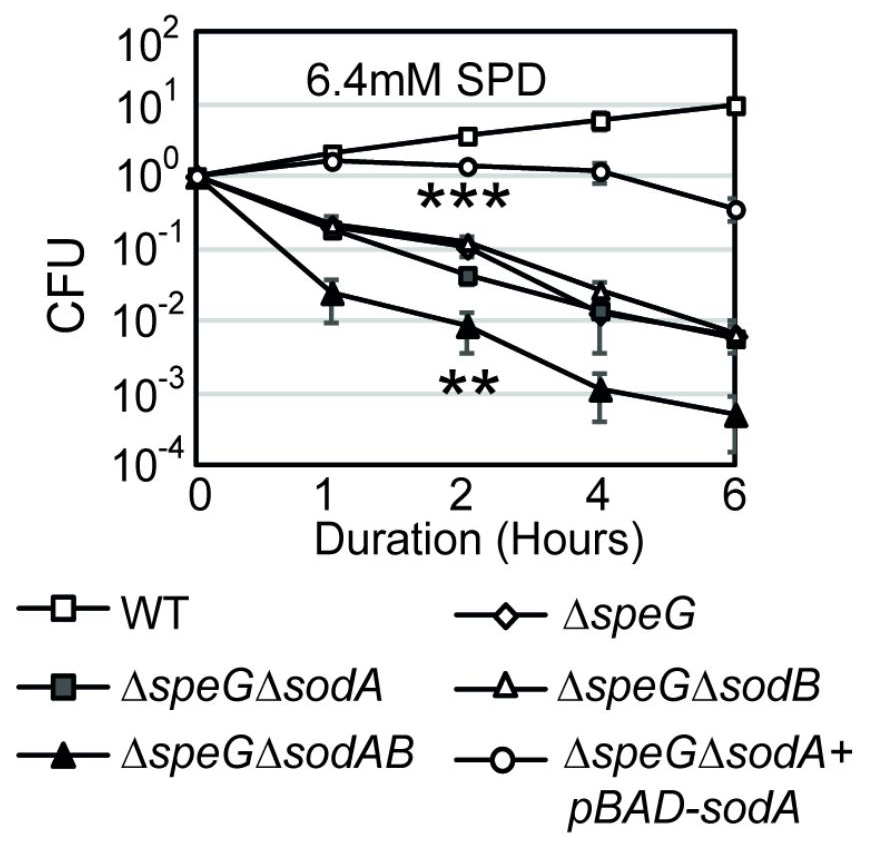


\section{Figure 2}

A.

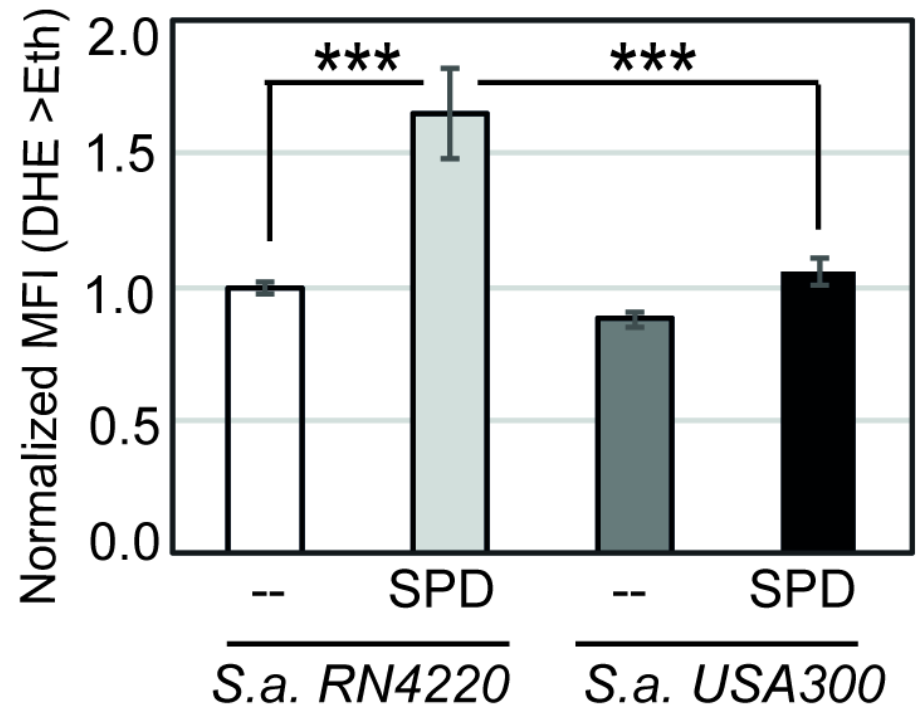

C.

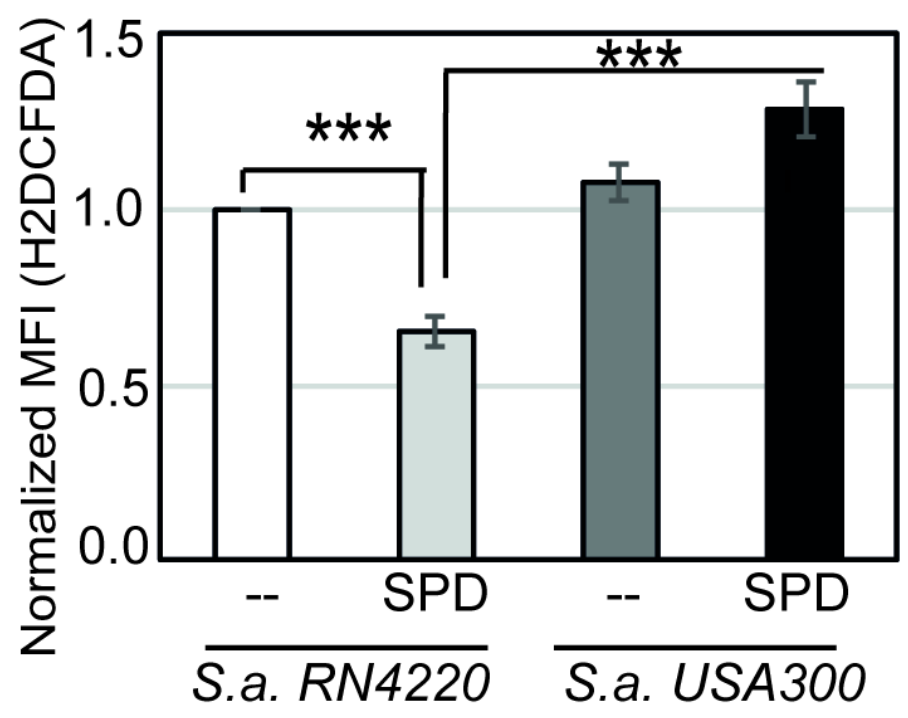

B.

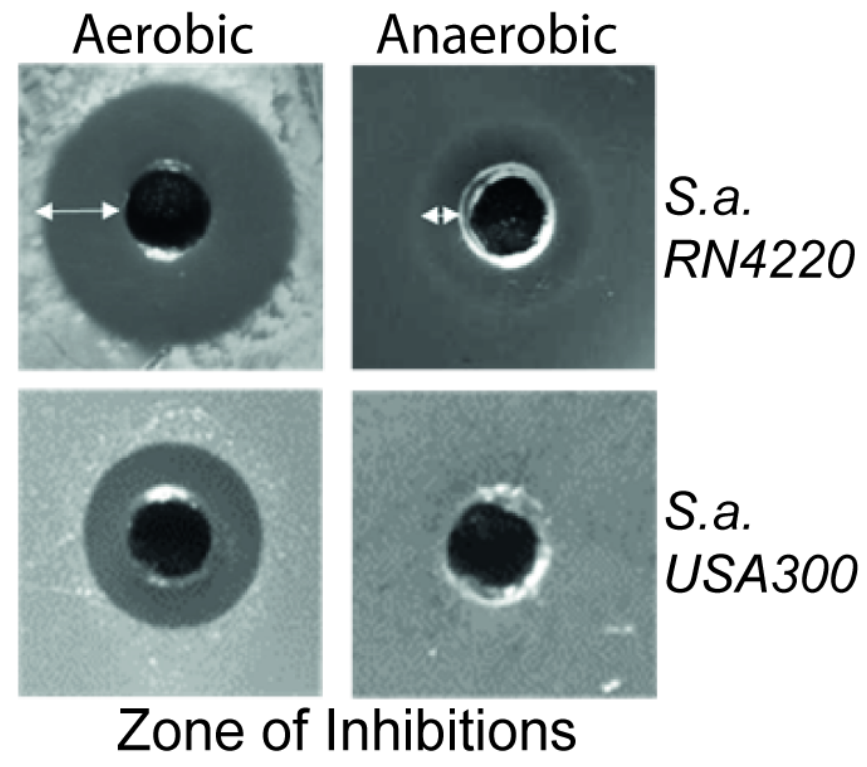

D.

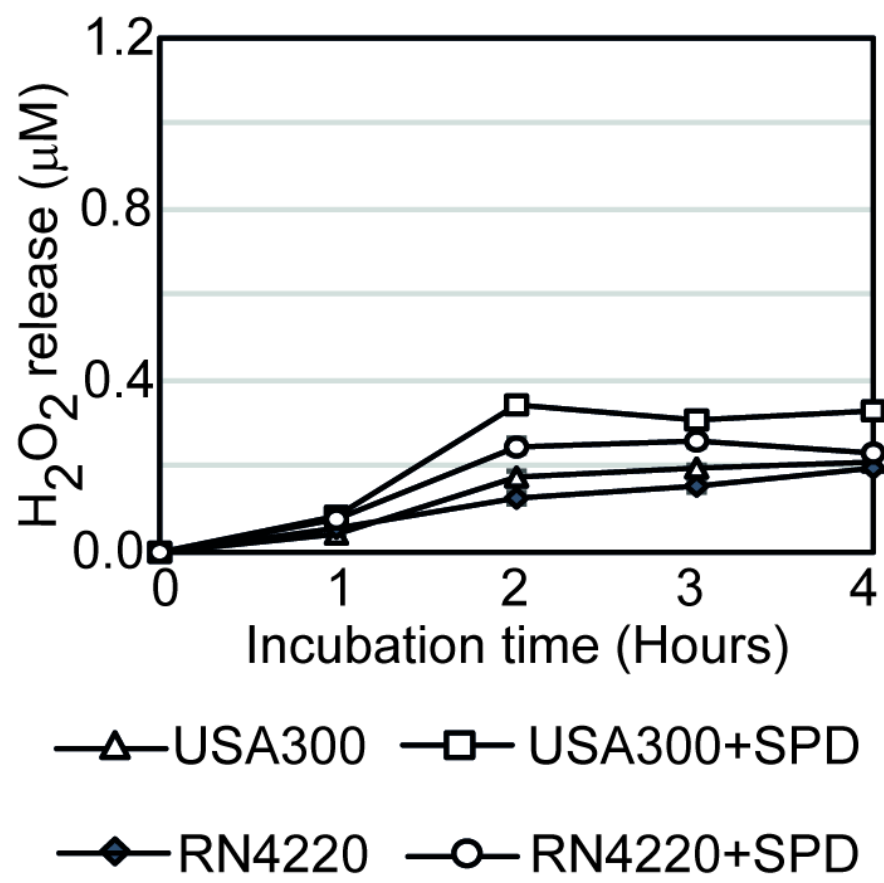


i. Microarray Fold change heat map

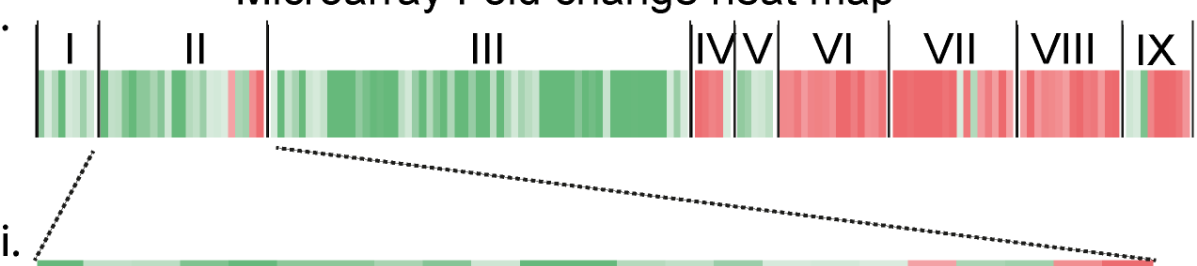

o N N ব워 .

iii.
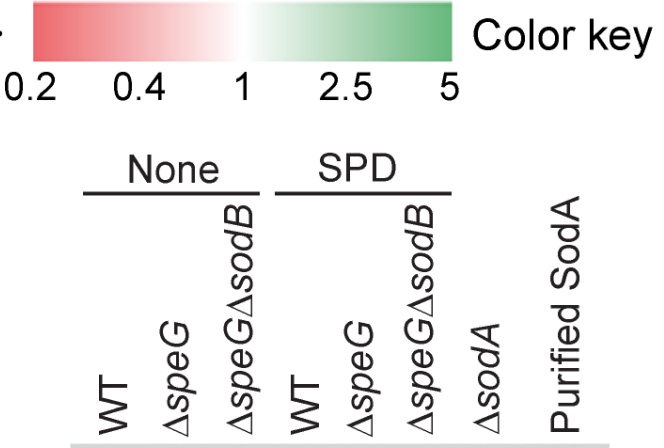

i.

ii.

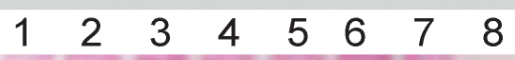

iii

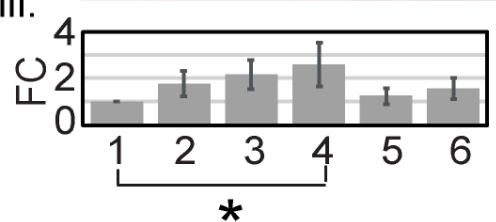

SodA -

?

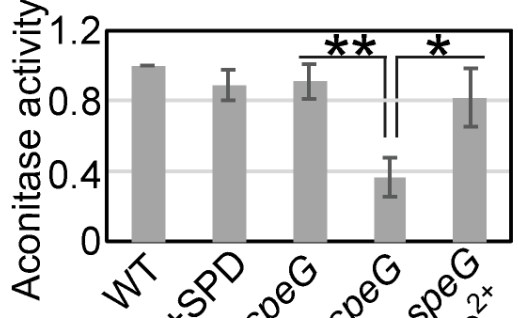
level

G

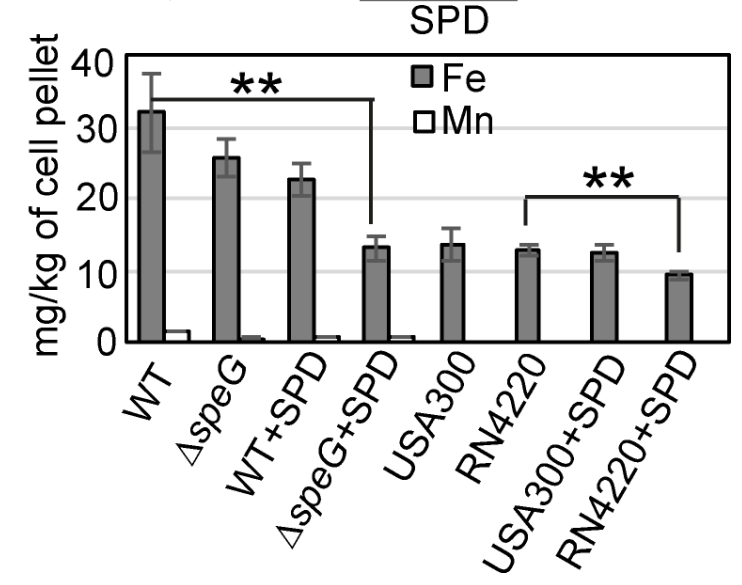

$\mathrm{H}$

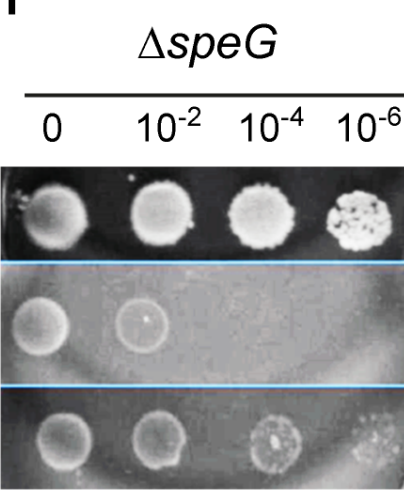

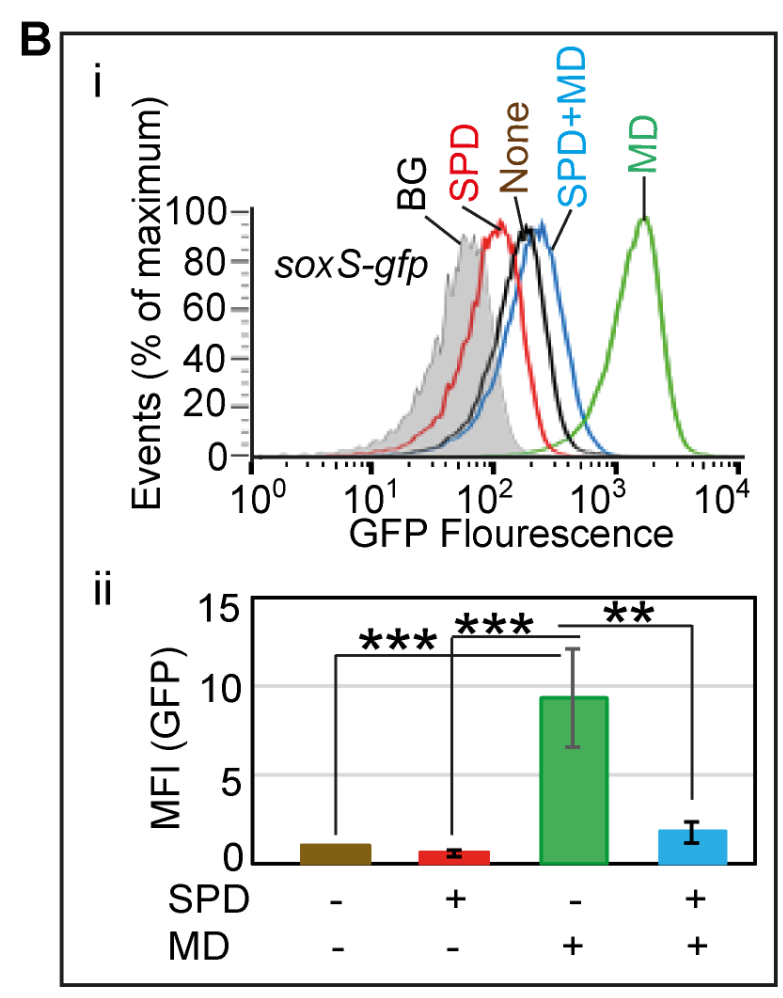

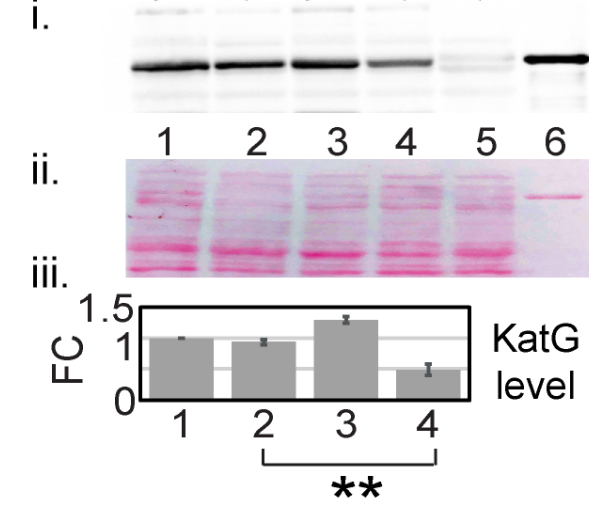

None

I

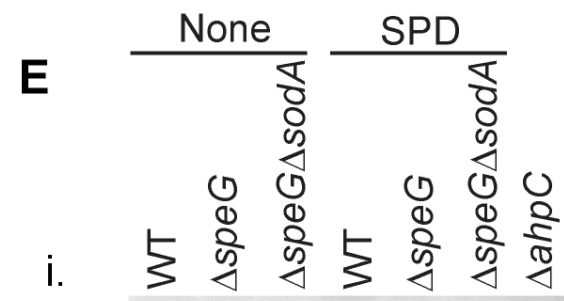

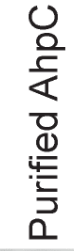

ii. $\begin{array}{lllllllll} & 1 & 2 & 3 & 4 & 5 & 6 & 7 & 8\end{array}$

iii.

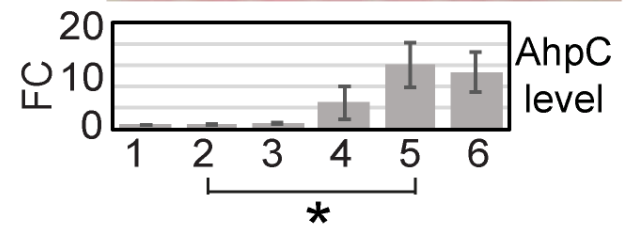
SPD SPD+ $\Delta s p e G \Delta i s c U$ $\mathrm{Fe}^{2+} \Delta s p e G \Delta s o x \mathrm{SO}$ 
Figure 6

$\mathrm{Fe}^{3+} / \mathrm{Fe}^{2+}$

$\mathrm{Fe}^{3+} / \mathrm{Fe}^{2+}$

$\mathrm{Fe}^{3+} / \mathrm{Fe}^{2+}$

$\mathrm{Fe}^{3+}$

\section{Spermidine}

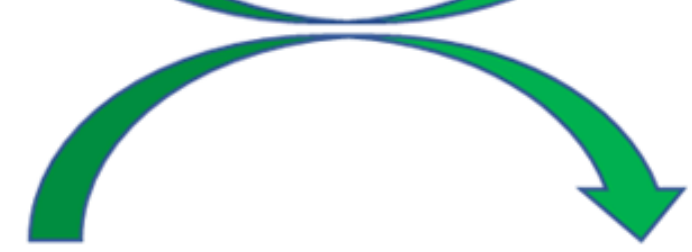

Spermidine

$\mathrm{O}_{2}$

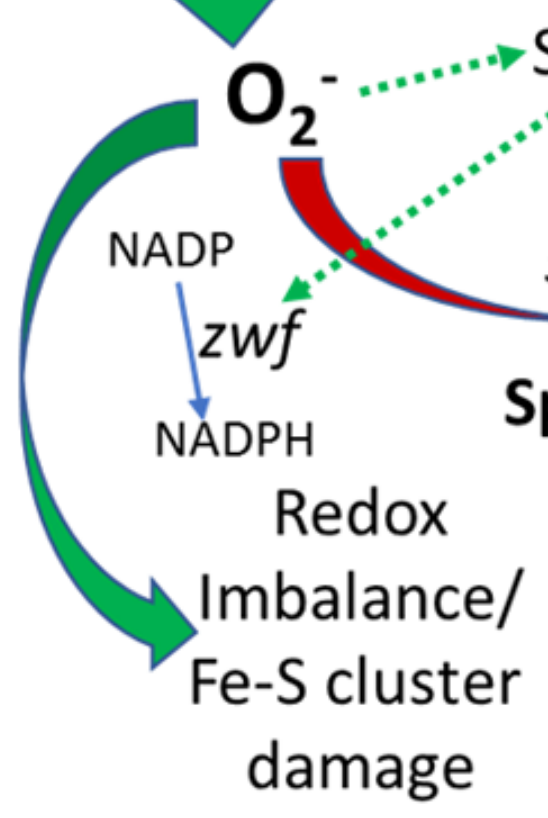

$\mathrm{H}_{2} \mathrm{O}$

Spermidine $\longrightarrow$ AhpCF 


\section{Figure 1 - figure supplement 1}

A.

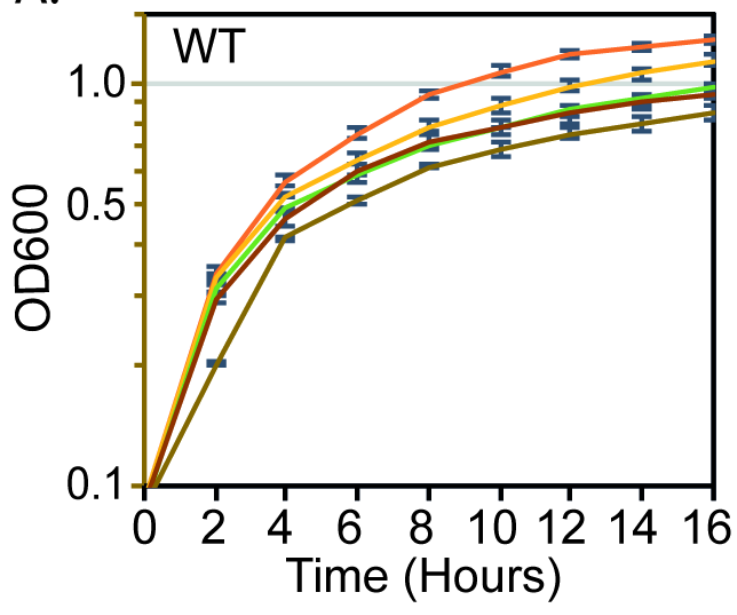

B.

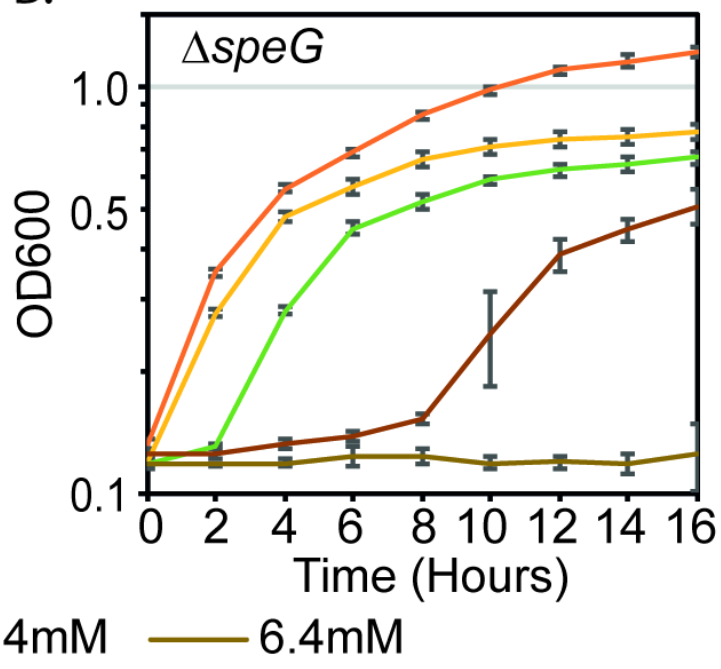

None

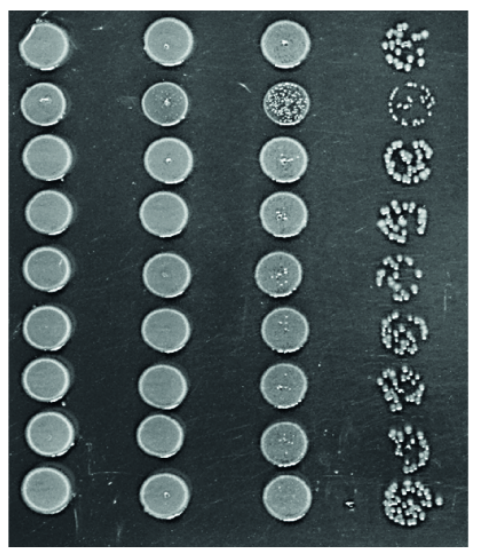

0
SPD $4.5 \mathrm{mM}$

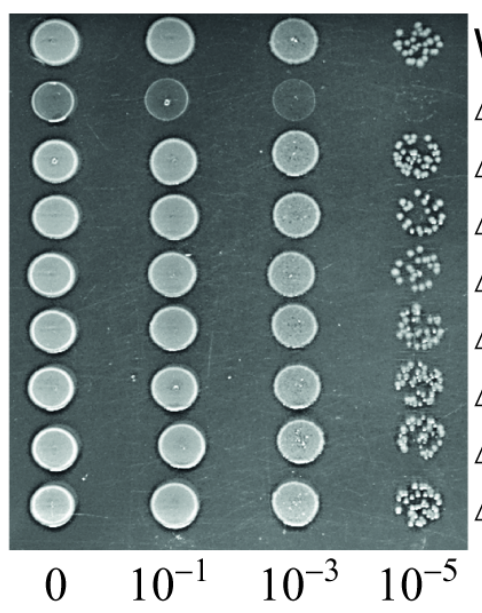

D.

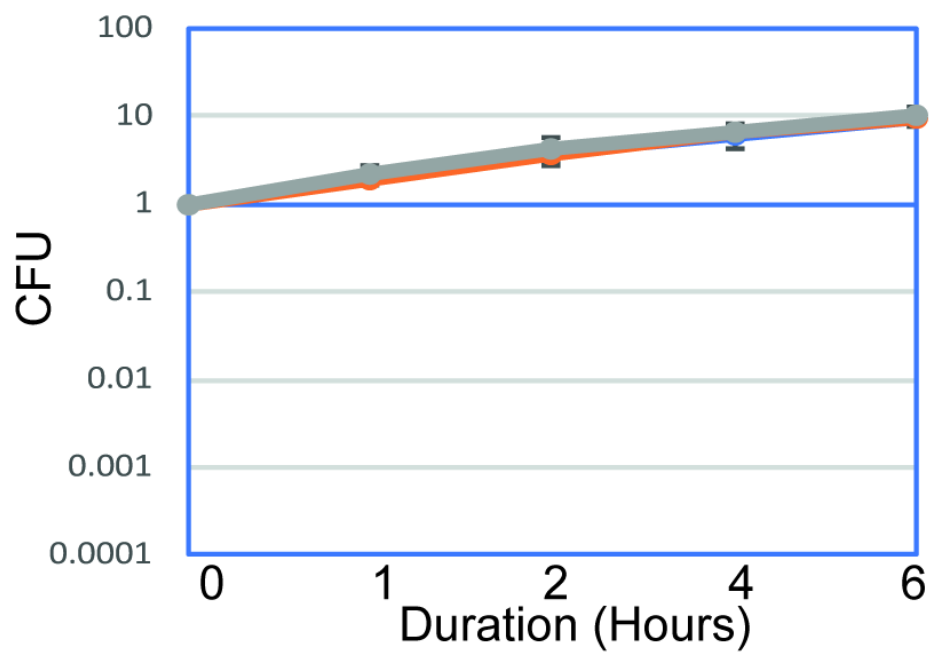




\section{Figure 4 - figure supplement 1}

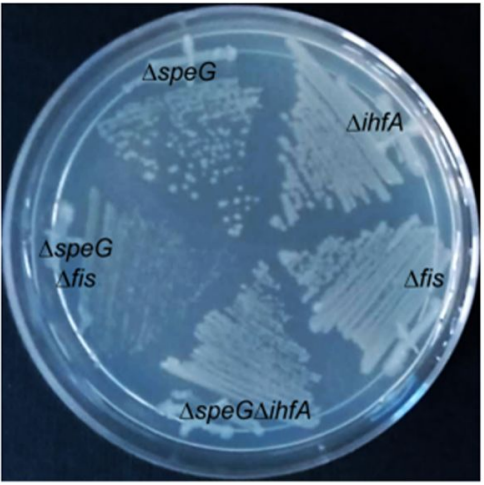


